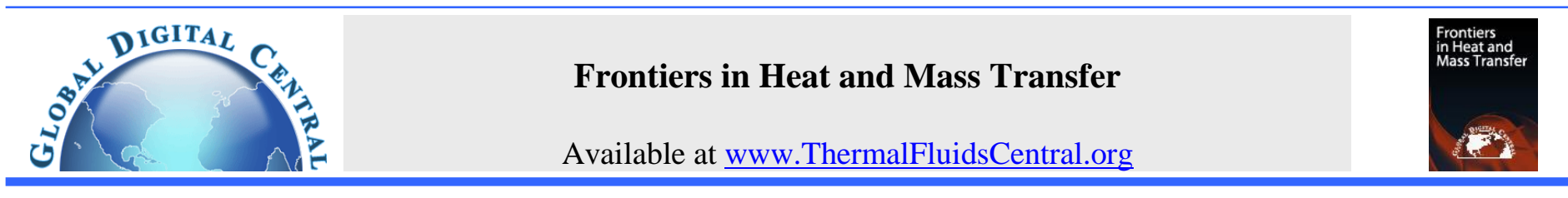

\title{
HYDRODYNAMIC AND THERMAL PERFORMANCE OF TWISTED TAPE INSERT PROVIDED IN HEAT EXCHANGER TUBES: A REVIEW
}

\author{
Ravi Datt ${ }^{\mathrm{a}, \mathrm{b}}$, Anil Kumar ${ }^{\mathrm{c}}$, Mangal Singh Bhist ${ }^{\mathrm{d}}$, Alok Darshan Kothiyal $^{\mathrm{e}}$, Rajesh Maithani ${ }^{\mathrm{f}}$ \\ ${ }^{a}$ Department of Applied Sciences, Chitkara University, Solan, Himachal Pradesh, 174103, India \\ ${ }^{b}$ Uttarakhand Technical University, Dehradun, Uttarakhand, 248007, India

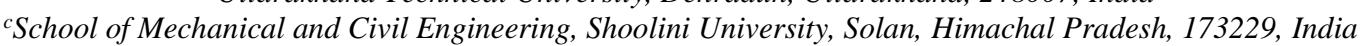 \\ ${ }^{d}$ Department of Mathematics, GBPEC, Pauri Garhwal, Uttarakhand, 246001, India \\ ${ }^{e}$ Department of Basic Science, BFIT, Dehradun, Uttarakhand, 248007, India \\ ${ }^{f}$ Department of Mechanical Engineering, DIT University, Dehradun, Uttarakhand, 248009, India
}

\begin{abstract}
This work presents a review of the research recent results concerning the augmentation of hydrodynamic and thermal performance of various twisted tape inserts in heat exchanger tubes. The thermal and hydrodynamic correlations for various twisted tape elements have been summarized. A comparative study of thermal and hydrodynamic performance of numerous twisted elements has also been reported to understand the result of applications of twisted tape inserts in heat exchanger tubes. The literature review found that multiple twisted tapes heat exchanger tube shape enhanced hydrodynamic and thermal performance than other comparable twisted tape inserts heat exchanger tube shapes. The review of twisted tape inserts techniques existing in this paper will be helpful to the investigators working in this field.
\end{abstract}

Keywords: Heat transfer; heat exchangers; passive techniques; fluid flow.

\section{INTRODUCTION}

Energy is a primary need to live our daily life at expenses of some valuable things such as environment degradation by using fossil fuels. Heat exchangers play a heating/cooling role in various fields like electric power, metallurgy, chemical engineering, refrigeration, and airconditioning etc by Sunil et al. (2019), Singh Suri et al. (2017) and Kumar \& Kim (2016). Circular tubes are widely used in heat exchange equipment's because of the ease of production and its capability of withstanding a high pressure Kumar et al. (2017) and Singh et al. (2018). Insertion of twisted tapes into a tube provides a simple passive technique for enhancing the heat transfer by introducing vortex generator into the bulk flow by breaking laminar sub layer at the tube wall due to repeated changes in the surface geometry. While insert technology is employed for augmented heat transfer, pressure drop would be improved by inserting in twisted tape in a tube Kumar et al. (2017), Singh et al.(2018), Yashwant Singh et al. (2018) and Maithani et al. (2019).

Twisted tapes with various shapes were proposed and utilized by various researchers. Numerous investigations have carried out the investigators in twisted tape inserts and thus, there is need to review the past and current research so that the further research scopes can be identified and implemented. The present article is thus aimed with following objectives:

- To review the augmentation in heat transfer and pressure drop in heat exchanger tubes equipped with various twisted tape inserts.

- $\quad$ To arrange the heat transfer and pressure drop correlations of a variety of twisted tape inserts in heat exchanger tubes.
- To carry out comparative study of heat transfer and pressure drop of heat exchanger tubes equipped with twisted tape insert.

In order to achieve the desired objectives, the article is structured batch wise for each objective clearly addressed and explained in their respective context.

\section{LITERATURE REVIEW ON TWISTED TAPE INSERT IN HEAT EXCHANGER TUBES}

Efforts for improving the thermal and hydrodynamic performance of heat exchangers have directed the investigation in the direction of disturbing the viscous sub layer by proving twisted tape inserts. Many investigations have been carried out to analysis the flow field characteristics of thermal and hydrodynamic of twisted tape insert tubes. Singh et al. (2017) examined the efficiency factor of twisted tape round tube for stable heat flux. The Reynolds number covered in the range of 6300 to 22500 for co-twist arrangements in the turbulent flow of air in the round tube. Kongkaitpaiboon et al. (2010) experimentally investigated the augmentation of thermal hydrodynamic performance in circular tube equipped with perforated conical rings. It was concluded that the augmentation in thermal and hydraulic performance achieved was 3.67 and 2.89 times more than plain circular tube, respectively. $\mathrm{Li}$ and Guo (2009) carried out experimental and numerical investigation of turbulent heat transfer and stream resistance in an improved round tube equipped with twisted tape inserts.

Promvonge (2008) experimentally studied the thermal and hydrodynamic performance of circular HET fitted with wire coiled inserts. The maximum value of thermal and hydrodynamic performance has been found to be 2.13 within the range of the parameters examined. Zhang and Zhang and Liu (2013) carried out numerical analysis of 3D turbulence fluid flow to study heat transfer and fluid flow 
characteristics for helical screw tape inserts without core rod inserts Shabanian et al. (2011) performed an experimental and computational analysis to study the thermal performance in an air cooled round tube fitted with three different types of tape inserts. Krishna et al. (2009) investigate thermal performance enhancement technique and concluded that heat transfer and friction factor enhancement in helical and leftright twisted tape collectors was better than the plain circular tube collector and it was 3.78 and1.45 times more than that of plain tube collector. Eiamsa-ard et al. (2006) carried out a comparative experimental study on thermal performance in a round tube with regularly spaced tape inserts and plane tube. The results of the study reveal that thermal performance increases with decrease of space ratio.

Naphon et al. (2006) carried out an experimental study to the behaviour of heat transfer and flow friction in horizontal double circular tubes equipped with tape inserts having length and thickness $2.0 \mathrm{~mm}$ and $0.01 \mathrm{~mm}$ respectively. Maddah et al. (2014) conducted an experimental investigation on heat transfer augmentation of Alumina/water nanofluid in a flat double circular tube with customized tape inserts. Sharma et al. (2009) experimentally examined the thermal performance by establishing mathematical relationship among Nusselt number and friction factor. The working Alumina/water nanofluid was circulated through a circular round tube of with tape inserts. Eiamsa-ard et al. (2012) carried out an experimental investigation to study thermal performance using helically inserts by using three different $\mathrm{y}_{\mathrm{rs}}$ and helical $\mathrm{H}_{\mathrm{rs}}$ 2.0-3.0. It was found that by inserting helically tape inserts the value of hydrodynamic and thermal performance was significantly higher than conventional helical tape. Eiamsa-ard and Wongcharee (2013) examined the thermal performance in circular tube fitted with dual tape inserts in three different types of geometrical configurations. Jaisankar et al. (2009) experimentally investigated the efficiency factor of twisted inserts with various spacer length inserts in a thermosyphon solar water heating system.

Jaisankar et al. (2008) conducted an experimental investigation on heat efficiency factor of solar heater's hose tube with tape inserts of various twist ratios. Jaisankar et al. (2011) conducted an experimental investigation to study the characteristics of hydrodynamic and thermal performance of water heat exchanger equipped with helical and leftright tape inserts. Eiamsa-ard and Promvonge (2011) investigated thermal performance for turbulent flow rate through a round tube equipped with straight tape with double sided delta wings. Nananet et al. (2014) carried out an experimental investigation to study heat transfer enhancement by perforated helical tape inserts in circular tube. Eiamsa-ard et al. (2010) conducted an experimental investigation to study thermal performance in a circular tube fitted with triple twisted tape inserts along with alternate clockwise and counter clockwise twisted tape inserts.

Sarada et al. (2010) studied the $\mathrm{Nu}_{\mathrm{rs}}$ increase in a round tube with changing breadth of tape inserts. Their outcome demonstrates that the utmost augmentation in thermal and hydraulic performance is observed to be 2.16 and 2.66 times of that of the plain round tube, respectively. Eiamsa-ard and Promvonge (2010) experimentally studied the thermal behaviour of plane circular pipe equipped with multi tape inserts along with various clock wise and counter clockwise tape inserts. Eiamsa-ard et al. (2006) experimentally studied the behaviour of flow friction and heat transfer in two-fold round tube fitted with tape inserts. A significant improvement were noticed in both flow friction and heat transfer. Eiamsa-ard et al. (2010) examined thermal performance in a round tube fitted with pooled devices among the tape inserts and steady or at regular intervals varying wire coil insert. Eiamsa-ard et al. (2010) experimentally investigated the efficiency factor in a circular pipe fitted with delta-winglet tape inserts. Sharma et al. (2003) explored a new method to enhance heat transfer in a round pipe equipped with twisted tape inserts. Sharma et al. (2005) discovered new mathematical generalized correlations for heat transfer and fluid flow for a round pipe fitted with twisted tape inserts. Yilmaz et al. (2003) carried out an experimental investigation to study the effects of special geometry of various components on efficiency factor. Chang et al. (2007) conducted an experimental investigation on twisted tape with cut and explored enhancement in performance of twisted tape with cut in comparison to smooth round tube. Chang et al. (2007) carried out an experimental investigation to study thermal performance in a round tube fitted with jagged tape inserts.

Seemawute and Eiasma-ard (2010) experimentally investigated the thermal performance through a round pipe having peripherally-cut twisted tape inserts. The thermal performance in round tube with peripherally-cut tape inserts with alternate axis, peripherally-cut tape inserts and multi tape inserts was found $23 \%, 45 \%$ and $62 \%$, respectively than that of plain round tube. Eiamsa-ard et al. (2010) experimentally examined the behaviour of thermal performance for a round tube fitted with sole tape inserts, complete length dual tape inserts and on a regular basis spaced dual tape inserts below identical wall heat flux circumstances. Bhuiya et al. (2013) experimentally examined the thermal performance for a turbulent flow through a round tube fitted with perforated tape inserts. The experimental consequences revealed a significant augmentation in thermal performance than the consequences of plain round tube. Karami et al. (2012) experimentally analysed the thermal performance in an air cooled round tube heat exchanger equipped with typical tape inserts. Murugesan et al. (2011) experimentally examined the efficiency factor for plain round pipe fitted with $\mathrm{V}$-cut tape insert.

Murugesan et al. (2010) experimentally investigated the thermal performance of a double round tube fitted with simple plane tape inserts and tape having wire nails. Murugesan et al. (2010b) experimentally investigated the efficiency factor for a double circular tube having square-cut tape inserts and plain tape inserts. Their results revealed that the thermal performance for round tube equipped with square-cut tape inserts were significantly more than plain tape inserts. Promvonge and Eiasma-ard (2007) experimentally studied the augmentation in thermal hydrodynamic performance of round tube attached with narrow conical ring. Nagarajan et al. (2010) experimentally examined the augmentation of thermal hydrodynamic performance of round tube attached with left-right tape inserts. New empirical correlations based on experimental data were introduced for thermal performance.

Thianpong et al. (2009) carried out an investigation to examine the thermal performance in a dimpled shape circular tube fitted with different tape inserts. Sivashanmugam and Suresh (2006) analysed the circular pipe fitted with helical twisted tape inserts experimentally. Sivashanmugam and Suresh (2007) experimentally determined the efficiency factor for circular pipe incorporated with various helical ST inserts having spacer distance end to end $100 \mathrm{~mm}, 200 \mathrm{~mm}, 300 \mathrm{~mm}$ and $400 \mathrm{~mm}$. Chang et al. (2009) experimentally examined the thermal performance in a round tube equipped with various tape inserts. Eiamsa-ard et al. (2009) experimentally examined the thermal performance in turbulent section for round tube fitted through small length tape inserts. Promvonge (2008) experimentally examined the thermal performance in turbulent flow within a round pipe fitted with wire coils shape inserts and tape inserts.

Bharadwaj et al. (2009) analysed the augmentation of thermal hydrodynamic performance of round tube attached with grooved twisted tapes. Mazumder and Saha [2008] experimentally investigated the thermal performance in heat exchanger fixed with tape inserts for turbulent flow. Murugesan et al .(2012) carried out an experimental investigation of thermal performance through circular tube incorporated with various twisted tape inserts. The range of Reynolds number ( $\left.\operatorname{Re}_{\mathrm{rs}}\right)$ was varied from 2000 to 12000 and water was taken as base fluid in the experiment. Wongcharee and Eiamsa-ard (2011) experimentally determined the thermal performance of round tube attached with customized tape inserts with alternating alignment. Zhang et al. (2012) experimentally examined the thermal performance in a round pipe with three and four tape inserts. Their analysis shows a significant improvement of thermal performance for three and four tape inserts. Ray and Date (2001) investigated thermal performance in heat exchanger fitted with tape inserts. The outcome of the analysis yields a significant improvement in thermal performance for twisted tape inserts 
as compared plain heat exchanger. Salam et al. (2013) conducted an experimental analysis to study the behaviour of flow friction and heat transfer in turbulent flow in a heat exchanger with rectangular slash tape inserts. Pal and Saha (2014) experimentally investigated the efficiency factor in a tube fitted with coiled corrugation roughness along with oblique teeth tape inserts. The working fluid in the experiment was taken viscous oil with laminar flow. Klaczak (2000) investigated the efficiency factor in round tube with erect copper pipe tape inserts. Experiments were carried out with air as working fluid and four tape inserts of twist ratio ranging from 1.63 to 5.28 and the range of Reynolds number varied from 110 to 1500. Rout and Saha (2013) examined the behaviour of heat transfer and pressure for laminar flow inside a round pipe with tape inserts constituted from wire coil helical screw.

Agarwal and Rao (1996) experimentally studied the augmentation of thermal hydrodynamic performance of double pipe with wire coiled inserts. The experiments examined double pipe in succession by keeping wall temperature constant. Sivashanmugam and Suresh (2006) experimentally examined the behaviour of heat transfer and pressure drop in laminar stream in circular pipe with twisted tape as inserts for twist ratio values of $1.94,2.92,3.92$, and 4.88. Wongcharee and Eiamsa-ard (2011) experimentally examined the thermal performance in round tube along with alternating anti-clockwise and clockwise tape inserts. It was found that the performance of round tube alternating anticlockwise and clockwise tape inserts significantly enhances the thermal performance as compared to tube with tape inserts. Sujoy et al. (2012) experimentally examined efficiency factor for laminar flow in round tube made up of circular passage with centre-cleared.

Sujoy (2012) experimentally examined laminar flow in a heat exchanger fitted with centre-cleared twisted tape insert. Ibrahim (2011) experimental examination to determine the efficiency factor in round tube was carried out with flat double round tube with full length helical screw tape inserts. Patil (1999) experimentally examined the performance of heat transfer in laminar flow in heat exchanger equipped with circular pipe and varying width tape inserts. Saha (2010) experimentally examined the behaviour of heat exchanger equipped with twist tape of square cut as well as rectangular segment with slanting ribs. Saha and Mallick (2004) experimentally examined the changes in behaviour of Nusselt number and flow friction of laminar stream through specially designed heat exchanger made up of duct shaving square cut and rectangular segment twisted tape with or without slanting teeth.

Pramanik and Saha (2006) experimentally examined the thermal performance in laminar stream flowing in round tube fitted with flat rectangular and square passage fitted tape inserts. Their investigation showed that the performance of twisted tape having regularly spaced geometry was improved than that full-length twisted tape inserts. Bilen et al. (2001) examined the heat transfer rate of heat exchanger tube equipped with rectangular blocks by using Taguchi method, considering angular displacement of the block with span and stream wise disposition. Kurtbas et al. (2009) experimentally examined the performances of heat transfer and friction loss in a round tube by constructing a novel conical twisted tape inserts. Al-Fahed et al. (1998) experimentally examined the behaviour of heat transfer and flow friction factor using oil as a functional fluid and then compared these results for a plain round tube, micro fins and tape inserts. Promvonge (2007b) carried out an experimental investigation to study the augmentation of thermal hydrodynamic performance of round tube fitted with numerous twisted tape shapes. In the experiment range of Reynolds number was varied from 3000 to 18000 laterally with three different pitch ratios ranging from 4.0 - 6.0. Chompookham et al. (2010) experimentally examine the behaviour of wedge obstacle and winglet vortex generators. It was discovered that the combined ribs and the WVG show the considerable enhancement in efficiency factor over the smooth passage. Bartwal et al. (2018) experimentally investigated passive heat transfer enhancement technique. Air was used as a working fluid with the range of Reynolds number varied from 5000 to 40,000.
The maximum TEF of 2.84 is retrieved for the $P R=3$, and $G=9$. Akhavan-Behabadi et al. (2010) experimentally studied the augmentation of thermal hydrodynamic performance of round tube attached with various coiled wires inserts. Meng et al. (2005) examined the thermal hydrodynamic performance of round tube attached with vortex generator. Their analysis showed that the DDIR tube inserts has better thermal performance than the other tubes.

Sarac and Bali (2007) experimentally studied the augmentation of thermal hydrodynamic performance of round tube attached with vortex generator. Their analysis showed that the decaying of the efficiency factor decreased steadily from the axial. Yang et al. (2011) investigated that the convergence of the tube can raise the stream rate which can decrease the turbulence generated in the stream and consequently there is decline in the heat transfer. Datt et al. (2018) presents the heat transfer and friction characteristics of turbulent circular tube flow through a square wing with combined solid ring twisted tape inserts have been analyzed experimentally. The finest value of thermal and hydrodynamic performance has been found to be 2.74 for of 3,000 within the range of the parameters investigated.

Hong et al. (2019) investigated turbulent thermal and fluid flow characteristics of multiple twisted tapes (MTTs) inserted sinusoidal rib tube (SRT) heat exchangers. The results ravelled that by inserting SRT there is increase in heat transfer enhancement of about $27.4 \%-39.5 \%$ and increased friction loss of around $49.4 \%-74.7 \%$ higher than that in the baseline of spirally corrugated tube (SCT), also the overall thermal performance was enhanced up to 1.59 for the alone use of SRT. Piriyarungrod et al. (2018) presents the thermo-hydraulic characteristics in the heat exchanger tube inserted with multiple-twisted tapes (M-TT). The experimental results found that the use of multiple-twisted tapes (M-TT) with $\mathrm{N}=3,4,5$ and 6 leads to the considerable increases in heat transfer enhancement and friction factor as compared to those of single twisted tape.

Farnam et al. (2018) explored that the heat transfer coefficient and pressure drop of the straight-tube and twisted-tube fitted with twistedtapes are higher than those of the straight-tube and twisted-tube alone, and evidently, both the parameters increase with the decrease in the twist ratio. Eiamsa-ard, and Wongcharee (2018) developed Micro-fin tubes into which non-uniform twisted tapes were inserted in a countercurrent arrangement gave higher heat transfer enhancement than the ones in a co-current arrangement. Karami et al. (2012) developed imperialist competitive algorithm is used to obtain optimize heat transfer rate in an air cooled heat exchanger fitted with the classic twisted tape inserts. According to the results, in order to obtain greatest heat transfer rate, the twist ratio must be at the lowest level.

Sarviya and Fuskele (2018) investigated heat transfer augmentation using a novel kind of twisted tape inserts with continuous cut edges. From obtained results it is evident that higher heat transfer rates can be achieved by employing twisted tape inserts with continuous cut edges at the cost of a reasonable pressure drop. Sarviya and Fuskele (2018) experimentally examined the thermal hydraulic performance of a heat exchanger tube equipped with various twisted tape widths and twist ratios. It can be seen that the combining effects of both the geometric and structural modifications, an improved design with optimum comprehensive performance was suggested.

Ayub et al. (2018) developed unique shell and tube heat exchanger with interstitial twisted tapes was tested with propylene glycol/water solution. From results it is clear new design heat exchanger showed better thermal enhancement index for the whole range of fluid concentrations. Lei et al. (2017) carried out numerical simulations to investigate the thermo-hydraulic performance of the two reformed shell-and-tube heat exchangers equipped with louver baffles. The numerical results revealed that the heat transfer coefficient per pressure drop of both the shell-and-tube heat exchangers with louver baffles are higher than that of the shell-and-tube heat exchanger with segmental baffles. Han et al. (2019) carried out multi-objective optimization of corrugated tube with loose-fit twisted tape to achieve the optimal performance, using response surface methodology and Non-dominated 
sorting genetic algorithm. The optimal design variables against $R e$ are also obtained, which carried out practical significances for designing perfect heat exchanger.

Li et al. (2019) a numerical investigation is conducted to investigate air side heat transfer and pressure drop performance of twisted oval tube bundles with in line layout in cross flow. The results revealed that the twisted oval tube bundles perform excellent heat transfer performance compared with other tube bundles in cross flow. Li et al. (2019) the ratio of outer major axis to outer minor axis, twist pitch length, transverse tube pitch, longitudinal tube pitch and number of longitudinal tube rows on the air side heat transfer tube and pressure drop performance are examined, which reveals that the twisted oval tube is an aerodynamic tube that is free of the angle of attack. Tan et al. (2012) concluded that the emergence of twist in the twisted oval tube results in secondary flow and it is this secondary flow that enhances the total velocity and temperature distributions of the twisted oval tube. Saravanan and Jaisankar (2019) examined that the helix with V cut twisted tape insert has given better thermal performance than helix with square cut twisted tape insert for an identical twist ratio. Aroonrat and Wongwises (2019) determine the influence of dimpled depth on the condensation heat transfer coefficient and pressure drop of R-134a flowing inside circular dimpled tubes. Wang et al. (2019) investigated the heat transfer performance in laminar flow of a round tube equipped with a longitudinal vortex generator. Results reveal that multiple pairs of additional longitudinal vortexes are developed, and the fluid can rub the tube wall due to the concave shape surface of the insert.

Ponnada et al. (2019) the effect of perforated twisted tapes with alternate axis, perforated twisted tapes and regular twisted tapes with different twist ratios are compared by experimental investigation in a circular tube under constant heat flux condition. At constant pumping power, the maximum thermal performance factor obtained is 1.433 , 1.396 and 1.24 respectively for perforated twisted tapes with alternate axis, perforated twisted tapes and regular twisted tapes. Abolarin et al. (2019) experimentally investigate the heat transfer and pressure drop characteristics in a smooth circular tube with alternating clockwise and counter clockwise twisted tape inserts. An increase in heat flux significantly enhanced the heat transfer in the laminar flow regime and delayed transition.

Geometries/parameters of various twisted tape inserts and correlations developed between the parameters by various investigators for heat transfer, pressure drop and thermal-hydraulic performance for different twisted tape inserts used in heat exchanger tubes are given in Table1.

\section{COMPARATIVE STUDY OF VARIOUS TWISTED TAPE INSERT HEAT EXCHANGER TUBES}

From the investigation of heat transfer and pressure drop it is concluded that heat transfer in the twisted tape inserts in round tube is improved with a significant rise in the pressure drop. Thus, it is important to choose twisted tape geometry that should not only outperformed in heat transfer but also retain the pressure drop at a minimum possible level. In order to achieve this goal of simultaneous consideration of thermal as well as hydraulic performance a parameter that is taken in consideration is known as efficiency parameter. The optimum data selected for various parameters of the tape inserts are like, twist length, twist ratio, pitch ratio, twist angle, etc. Thermal hydraulic performance parameter of various twisted tapes has been determined using their corresponding correlations of heat transfer rate; friction factor and thermal hydraulic performance as listed in Table 1.

Figure 1 represents the multiple twisted tape inserts shape that provides the utmost value of thermal hydraulic performance with air as test fluid among all the twisted tape shapes examined. Figure 2 represents the multiple spiky twisted tape inserts shape that provides the utmost value of thermal hydraulic performance with water as test fluid among all the twisted tape shapes examined. Figure 3 represents the circular with center cleared twisted tape inserts shape provides the utmost value of thermal hydraulic performance with oil as test fluid among all the twisted tape shapes examined. In a dynamic air field stream, the roughness creates turbulence and improves the heat transfer/exchange by convection. The literature reveals that single twisted tape inserts in a tube of heat exchanger thermohydrodynamically performs best as compared to delta and helical twisted tape inserts, as the twist ratio induces multiple vortex stream cells which helps to enhancement of local heat transfer rate. Various investigators concluded that multi type twisted tape inserts in heated tube surface of a heat exchanger tube boost up the rate of heat transfer. Further it was concluded that the utilization of multiple twisted tape increases the number of vortex flow as compared to single twisted tape inserts, which helps to increase the heat transfer rate, as shown in Figure 4.

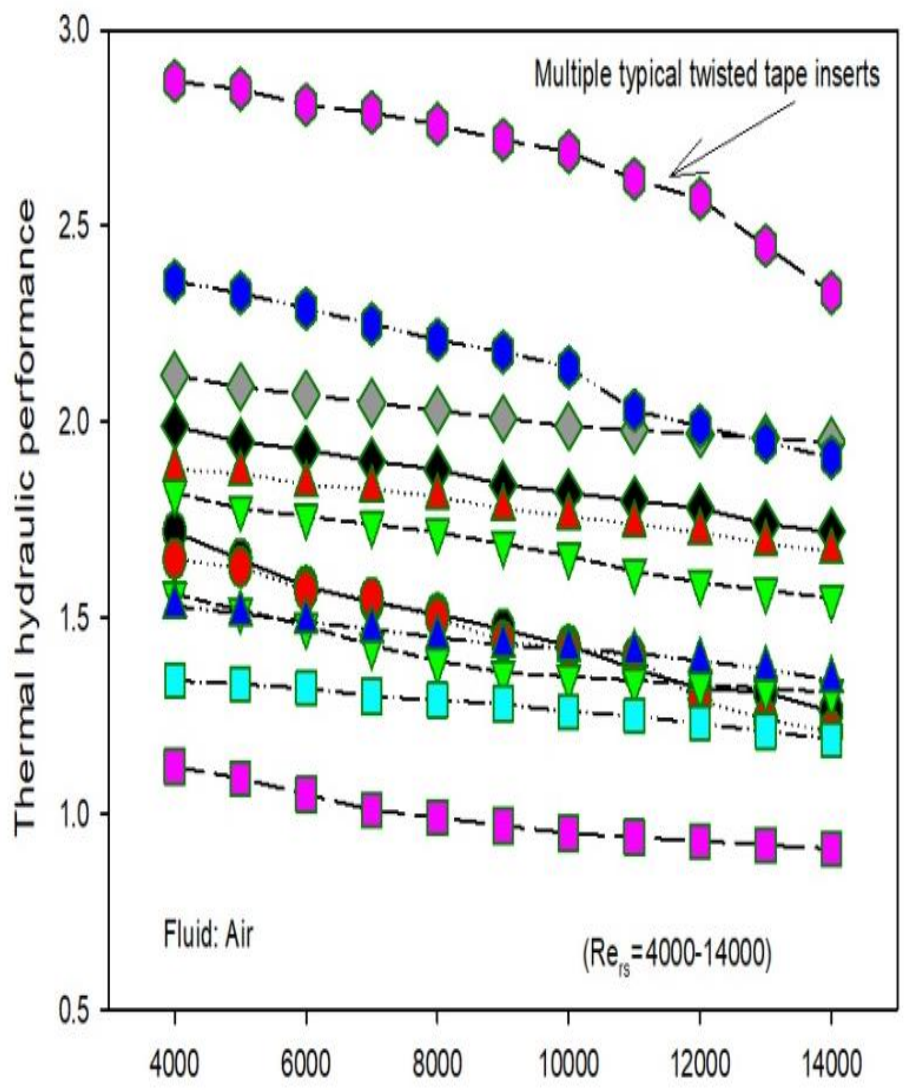

Reynolds number

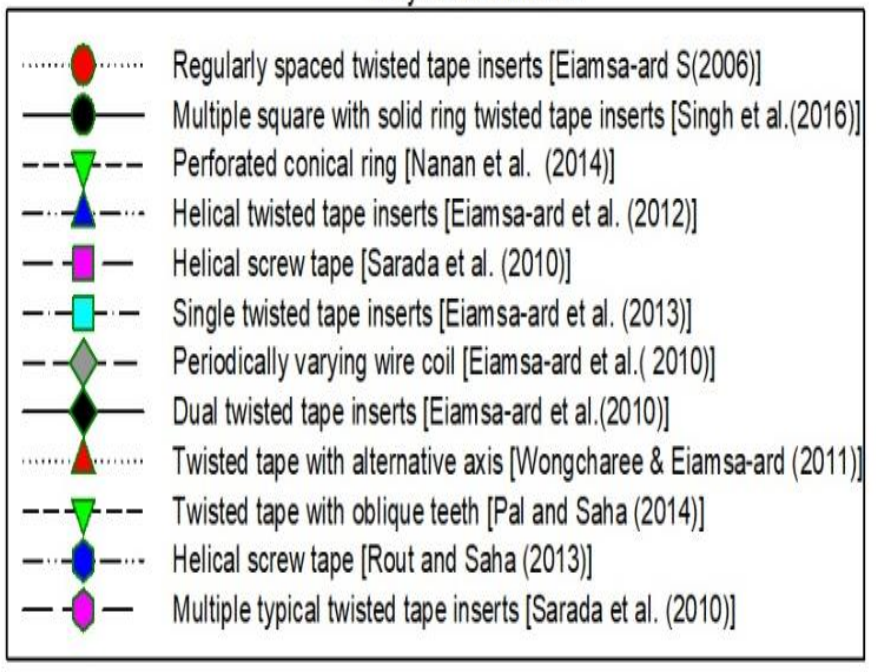

Fig. 1 Comparison of thermal hydraulic performance as function of Reynolds number for different type of twisted tape inserts with air as working fluid. 


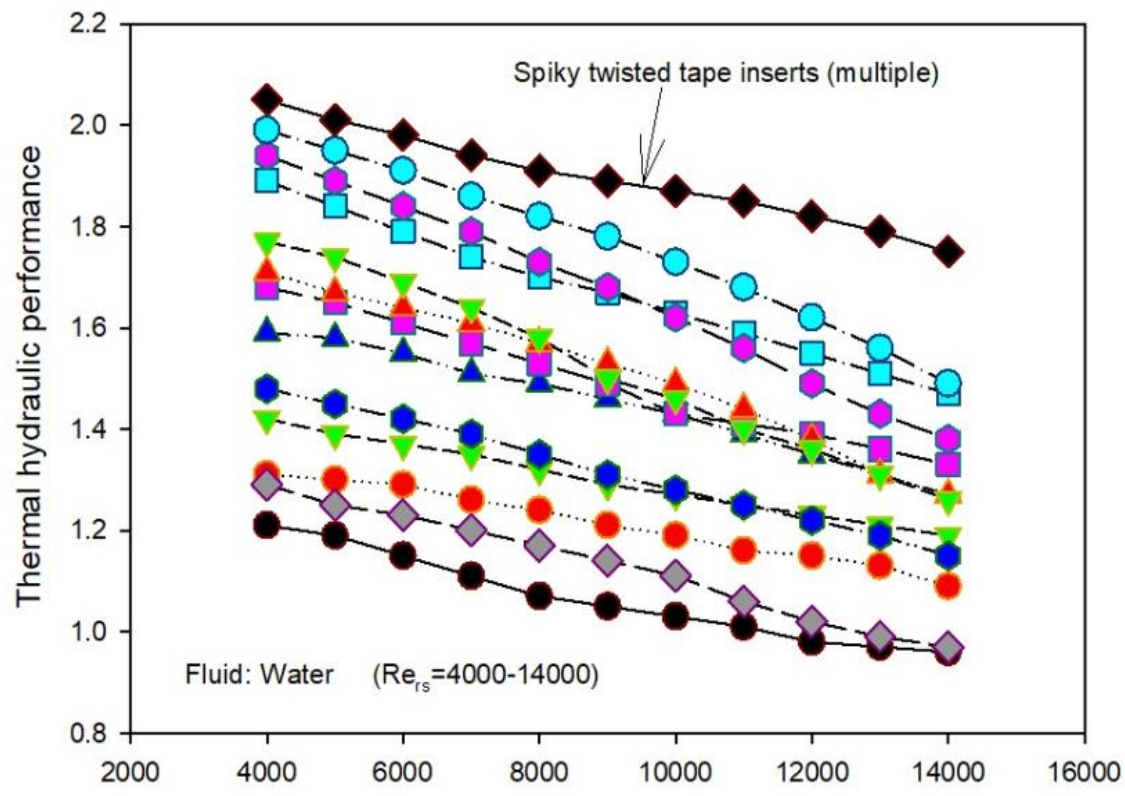

Revnolds number

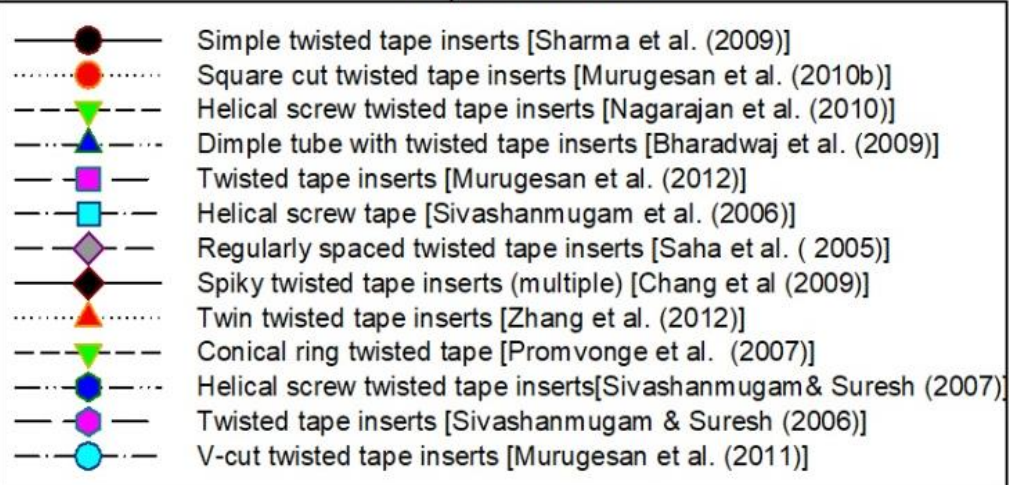

Fig. 2 Comparison of thermal hydraulic performance as function of Reynolds number for different type of twisted tape inserts with water as test fluid.

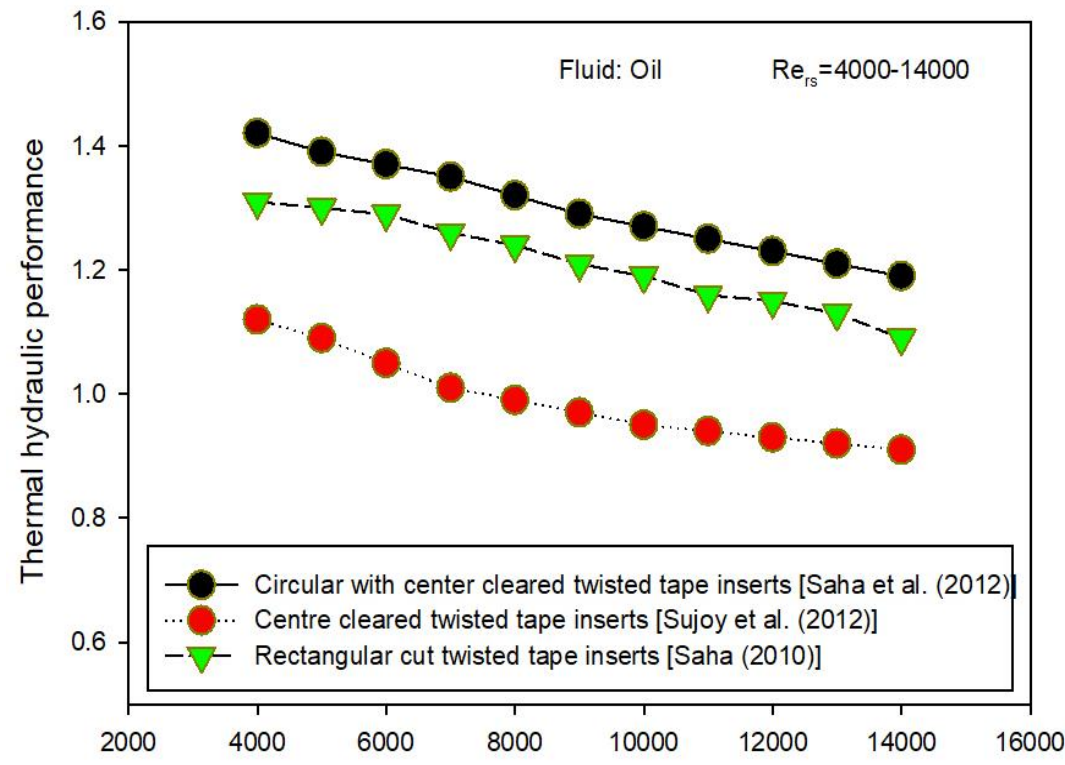

Reynolds number

Fig. 3 Comparison of thermal hydraulic performance as function of Reynolds number for different type of twisted tape inserts with oil as test fluid. 
Table 1 Correlations developed for heat transfer; pressure drop and thermal hydraulic performance in twisted tape insert heat exchanger tubes.

$\begin{array}{ccc}\text { Twisted tape geometry } & \begin{array}{c}\text { Parameters/optimum } \\ \text { ranges }\end{array} & \text { Correlations } \\ \text { Working fluid: Air } & \text { rang }\end{array}$

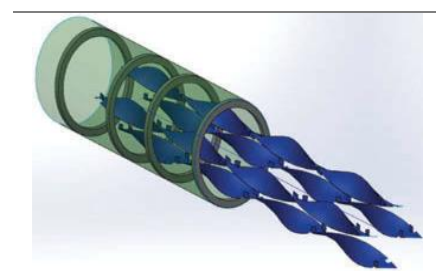

Tube with solid rings and square wings TT inserts. Datt et al. (2018).

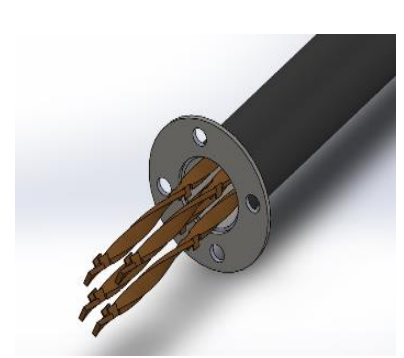

Multiple squares perforated twisted tapes inserts. Singh $e t$ al. (2017).

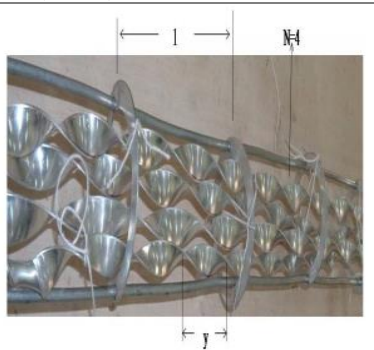

Solid ring with multiple twisted tapes inserts. Singh et al. (2016).

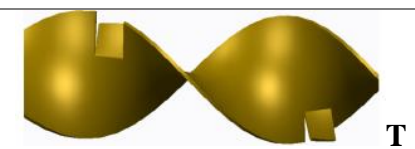

wisted tape inserts with and without oblique teeth. Pal and Saha (2014).

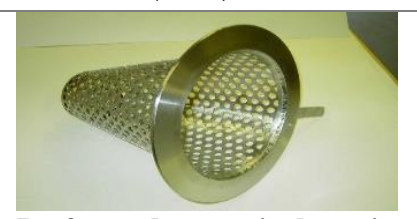

Perforated conical ring twisted-tapes. Nanan et al. (2014).
Fluid: Air

Parameters:

$3000 \leq \mathrm{Re}_{\mathrm{rs}} \leq 21000$

$N T T=1.0-4.0, d R=D T=$ $0.5-2.0, P W=W T$

$=2.0-3.5, \quad W d=W T=$ $0.083-0.333$,

$N u_{r s}=283, \mathrm{f}_{\mathrm{rs}}=0.62$

$\eta_{\rho}=1.29$ and 2.74

Fluid: Air

Parameters:

$5000 \leq R e_{r s} \leq 24000$

$a / W_{T}$ of 0.250 and

$T_{L} / W_{T}$ of 2.5

Minimum and maximum values of results:

$N u_{r s}=2.12-5.69$

$f_{r s}=0.15$ -

0.32 ,

$\eta_{\rho}=2.2-3.8$.

Fluid: Air

Parameters:

$6300 \leq R e_{r s} \leq 22500$

Twist ratios 2, 3, and 4 .

Minimum and maximum

values of results:

$N u_{r s}=20-120$

$f_{r s}=0.010-0.027$,

$\eta_{\rho}=1.6-2.0$.

Fluid:Air, Parameters:

$\mathrm{y}_{\mathrm{rs}}=2.20$ and 5.0.

Minimum and maximum values of results:

$N u_{r s}=5-57$

$f_{r s}=0.2-1.2$,

$\eta_{\rho}=1.3-1.82$.

Fluid: Air

Parameters:

$6000 \leq R e_{r s} \leq 20000$,

Pitch ratios $=4.0,6.0$

12.0. Holes perforation $\mathrm{N}$ $=4,6$ and 8 .

Minimum and maximum

values of results:

$N u_{r s}=24-94$

$f_{r s}=0.03-.042$,

$\eta_{\rho}=1.28$.
$N u_{T T}=0.0007 R e^{0.74}\left(d_{R} / D_{T}\right)^{0.17} B_{o}\left(d_{R} / D_{T}\right)^{0.17}$

$\exp \left[-0.18 \ln \left(d_{R} / D_{T}\right)^{2}\right]\left(P_{W} / W_{T}\right)^{2.53}$

$\exp \left[-1.26\left(\ln \left(P_{W} / W_{T}\right)\right)^{2}\right] \times\left(W_{d} / W_{T}\right)^{-0.78}$

$\times \quad \exp \left(-0.19\left(\ln \left(W_{d} / W_{T}\right)\right)\right)^{2}$

$\times\left(d_{i R} / d_{o R}\right)^{7.57} \exp \left(-2.3\left(\ln \left(d_{i R} / d_{o R}\right)\right)\right)^{2} \times\left(N_{T T}\right)^{0.69} \exp \left(-0.25\left(\ln \left(N_{T T}\right)\right)\right)^{2}$ and

$f_{T T}=0.47 R e^{-0.128}\left(d_{R} / D_{T}\right)^{1.97}$

$\exp \left(-0.047\left(\ln \left(d_{R} / D_{T}\right)\right)\right)^{2}\left(P_{W} / W_{T}\right)^{-0.022}$

$N u_{r s}=R e_{n}^{0.9204} \times\left(a / W_{T}\right)^{-1.062} \operatorname{Exp}\left(-0.329\left(\ln \left(a / W_{T}\right)\right)^{2} \times\left(T_{L} / W_{T}\right)^{1.8701} \operatorname{Exp}\left(-1.136 \ln \left(T_{L} / W_{T}\right)^{2}\right)\right.$

$f_{r s}=2.68 R e_{n}{ }^{-0.4077}\left(a / W_{T}\right)^{-0.9735} \operatorname{Exp}\left(-0.2978 \ln \left(a / W_{T}\right)\right)^{2}$

$$
\times\left(a / W_{T}\right)^{1.841}
$$$$
\times \operatorname{Exp}\left(-1.2398 \ln \left(T_{L} / W_{T}\right)^{2}\right)
$$

$\eta_{p}=1.64 \times 10^{-2} R e_{n}^{0.3389} \times\left(a / W_{T}\right)^{-0.5337} \operatorname{Exp}\left(-0.1625\left(\ln \left(a / W_{T}\right)\right)^{2} \quad \times\left(T_{L} / W_{T}\right)^{3.7071} \operatorname{Exp}\left(-2.1598 \ln \left(T_{L} / W_{T}\right)^{2}\right)\right.$
$N u_{r s}=0.09653\left(R e_{r s}^{0.7834}\right) N^{0.0551} \exp \left(0.0256 \ln N^{2}\right) T R^{0.2127}$

$\exp \left(-0.1696 \ln T R^{2}\right)$

$f_{r s}=1.073\left(R e_{r s}{ }^{-0.0786}\right) N^{0.0352} \exp \left(0.1094 \ln N^{2}\right) T R^{0.4696}$

$\exp \left(-0.3760 \ln T R^{2}\right)$

$\eta_{r s}=3.033\left(\operatorname{Re}_{\mathrm{rs}}{ }^{-0.0786}\right) N^{0.0188} \exp \left(0.1063 \ln N^{2}\right) T R^{0.1304}$

$\exp \left(-0.0968 \ln T R^{2}\right)$

$N u_{r s}=0.0832\left(\operatorname{Re}_{\mathrm{rs}}{ }^{0.7899}\right) N^{0.0383} \exp \left(0.0355 \ln N^{2}\right) T R^{0.23757}$

$\exp \left(-0.2488 \ln T R^{2}\right)$

$f_{r s}=1.042\left(\operatorname{Re}_{\mathrm{rs}}{ }^{-0.0539}\right) N^{0.0873} \exp \left(0.0772 \ln N^{2}\right) T R^{0.4780}$

$\exp \left(-0.3660 \ln T R^{2}\right)$

$\eta_{r s}=2.94\left(\operatorname{Re}_{\mathrm{rs}}{ }^{-0.0771}\right) N^{0.0072} \exp \left(0.0237 \ln N^{2}\right) T R^{0.1097}$

$\exp \left(-0.0814 \ln T R^{2}\right)$

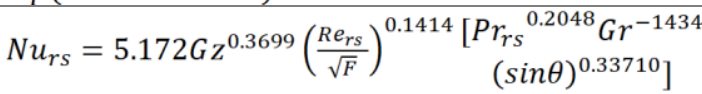

$f_{r s}=17.355\left(R e_{r s} / \sqrt{V}\right)^{0.043491}$

$(\sin \alpha)^{-0.100061} h_{c}{ }^{-0.8215} t_{h l}{ }^{-0.07074}(\sin \theta)^{-0.375767}$

$N u_{r s}=0.035 R e_{r s}{ }^{0.795} \operatorname{Pr}_{r s}{ }^{0.4}(d / w)^{-0.068}(s / w)^{0.066}$,

$f_{r s}=1.915 R e_{r s}{ }^{-0.299}(d / w)^{-0.068}(s / w)^{0.994}$ and

$\eta_{r s}=4.058 R e_{r s}{ }^{-0.145}(d / w)^{-0.045}(s / w)^{0.045}$ 


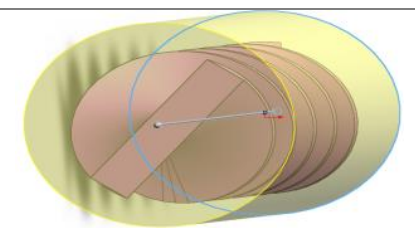

Micro-fins tubes. Eiamsaard et al. (2013).

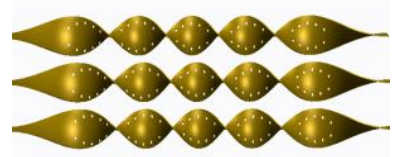

Perforated twisted tape insert. Bhuiya et al. (2013).

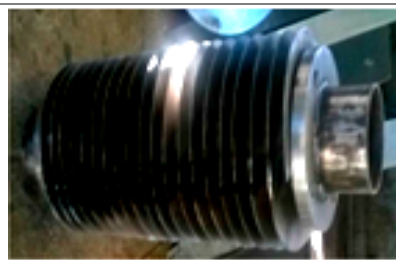

Helical screw-tape .Kumar $e t$ al. (2013).

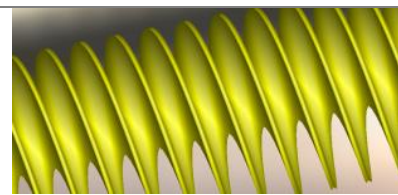

Classic twisted tape inserts. Karami et al. (2012).

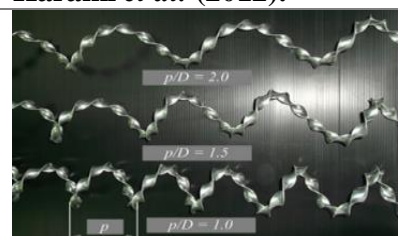

Helical twisted tape. Eiamsaard et al. (2012).

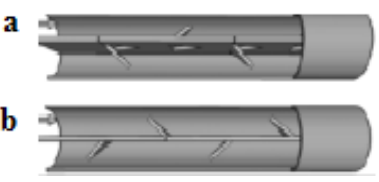

(a)TT with back wing. (b)TT with forward wing. Eiamsaard et al. (2011).

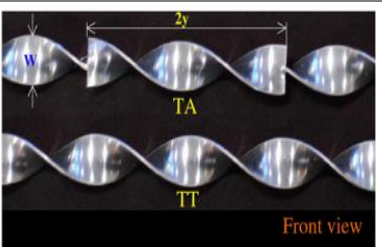

Twisted tape with alternate axis.

Wongcharee and Eiamsa-ard (2011).
Fluid:

Parameters:

$5660 \leq R e_{r s} \leq 17000$.

Minimum and maximum

values of results:

$N u_{r s}=39-410$

$f_{r s}=0.5-0.46$,

$\eta_{\rho}=1.1-1.94$.

Fluid: Air

Parameters:

$72000 \leq R e_{r s} \leq 50,200$

Minimum and maximum

values of results:

$N u_{r s}=80-290$

$f_{r s}=0.0320 .14$,

$\eta_{\rho}=1.3-1.6$.

Fluid: Air

Parameters:

$10 \leq \operatorname{Re}_{\mathrm{rs}} \leq 1000$

Wire diameter 0.0769 ,

0.1026 )

Helix angle $30^{\circ}, 60^{\circ}$ )

Minimum and maximum

values of results:

$N u_{r s}=5-132$,

$f_{r s}=0.02-1.2$,

$\eta_{\rho}=1.45-1.71$

Fluid: Air

Parameters:

$4021 \leq R e_{r s} \leq 16116$

$\mathrm{y}_{\mathrm{rs}}=1.75,2.3,2.9$ and 3.5

Minimum and maximum

values of results:

$N u_{r s}=49.07-116.19$

Fluid: Air

Parameters:

$2000 \leq \operatorname{Re}_{\mathrm{rs}} \leq 6000$

$2, \mathrm{y}_{\mathrm{rs}}=2.0,2.50,3.10$.

Pitch ratios $1.5 \& 3.0$.

Minimum and maximum

values of results:

$N u_{r s}=35-120$

$f_{r s}=0.03-0.042$,

$\eta_{\rho}=1.29$.

Fluid: Air

Parameters:

$4000 \leq R e_{r s} \leq 20000$

Wing width ratios of 0.5 ,

0.67 and $0.83 . \mathrm{y}_{\mathrm{rs}}=0.75$,

1.0 and 1.25 .

Minimum and maximum

values of results:

$N u_{r s}=35-147$

$f_{r s}=0.25-0.50$,

$\eta_{\rho}=1.19$.

Fluid: Air

Parameters:

$830 \leq R e_{r s} \leq 1990$

$\mathrm{y}_{\mathrm{rs}}=3.0$, Density of nanofluid varied from

$0.30 \%$ to $0.70 \%$.

Minimum and maximum

values of results:

$N u_{r s}=12-67$

$f_{r s}=0.32-0.67$.

$\eta_{\rho}=1.5-5.4$.

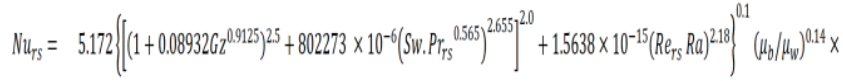

$[1+\exp (0.08858 p)]$

$+\left[1+\exp (0.08135 \cdot \sin \theta) /\left(d / D_{r s}\right)^{-0.6683}\right]\left({ }^{\prime} \theta '=\right.$ coil helix

angle). $\quad f_{r s}=17.355\left(\frac{\pi+2-2 \delta / D_{r s}}{\pi-4 \delta / D_{r s}}\right)^{2}$

$\left(1+10^{-6} S w^{2.67}\right)^{1 / 7} \times\left[1+\exp (0.05538 . \sin \theta) /\left(d / D_{r S}\right)^{-0.6938}\right][1+\exp (0.0785 p)]$

$N u_{r s}=90.2+14.7 R e_{r s}-3.72 R-0.276 R e_{r s}^{2}-0.539 R e_{r s} \times R$
$N u_{r s}=0.101 R e_{r s}{ }^{1.73} \operatorname{Pr}_{r s}{ }^{0.4}\left(e_{p}\right)^{-0.265}\left(e_{w}\right)^{-0.287}$ and

$f_{r s}=0.898 R e_{r s}{ }^{0.994} \operatorname{Pr}_{r s}{ }^{0.4}\left(e_{p}\right)^{-0.516}\left(e_{w}\right)^{0.656} \quad(\mathrm{~T}-\mathrm{W}$ towards

the back wing set up)

$N u_{r s}=0.11 R e_{r s}{ }^{0.731} \operatorname{Pr}_{r s}{ }^{0.4}\left(e_{p}\right)^{-0.283}\left(e_{w}\right)^{-0.316}$ and

$f_{r s}=0.55 R e_{r s}{ }^{-0138}\left(e_{p}\right)^{-0.635}\left(e_{w}\right)^{0.759}$

(T-W towards the back wing set up)
$N u_{r s}=0.026 R e_{r s}{ }^{0.927}\left(P r_{r s}\right)^{0.4}\left(\phi_{r s}+1\right)^{0.128}$ (Tube with TT with alternative axis) $N u_{r s}=0.0050 R e_{r s}^{1.0620}\left(P r_{r s}\right)^{0.40}\left(\phi_{r s}+1\right)^{0.112}$

(Tube with TTT) $f_{r s}=4.487 R e_{r s}{ }^{-0.297}\left(\phi_{r s}+1\right)^{0.1001}$

$f_{r s}=3.234 R e_{r s}{ }^{-0.308}\left(\phi_{r s}+1\right)^{0.082}($

$\eta_{r s}=0.027 \operatorname{Re}_{r s}{ }^{0.693}\left(\phi_{r s}+1\right)^{0.094}$

$\eta_{r s}=0.0060 R e_{r s}{ }^{0.8320}\left(\phi_{r s}+1\right)^{0.0850}$ 


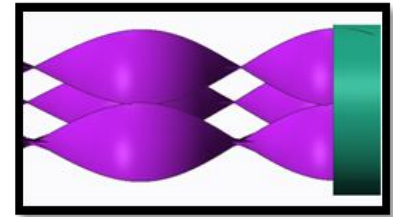

Multiple typical twisted tapes. Sarada et al. (2010).
Fluid: Air

Parameters:

$6000 \leq R e_{r s} \leq 13500$

Widths of the TT $10.0 \mathrm{~mm}$

to $22.0 \mathrm{~mm}$.

Minimum and maximum values of results:

$N u_{r s}=30-45$

$f_{r s}=0.0072-0.0079$,

$\eta_{\rho}=1.1-1.7$.

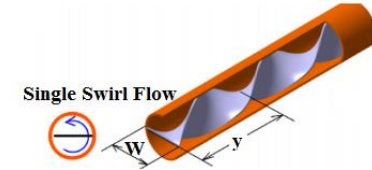

Single, twin co- twisted and twin counter twisted tape. Eiamsa-ard et al. (2010).

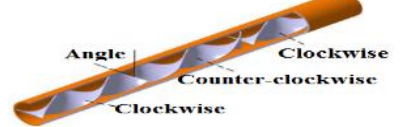

Clockwise and counterclockwise twisted-tape inserts. Eiamsa-ard et al. (2010).

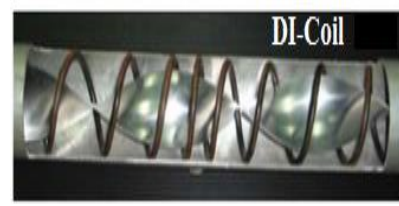

Periodically varying wire coil.

Eiamsa-ard et al. ( 2010).

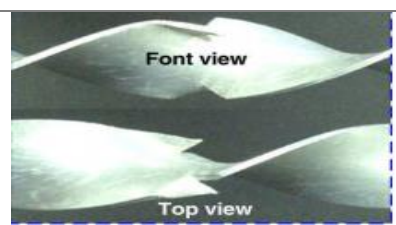

Delta-winglet twisted tapes. Eiamsa-ard et al. (2010).

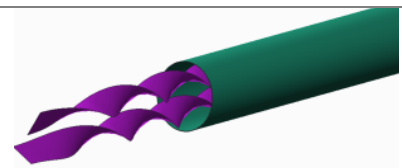

Dual twisted tape inserts. Eiamsa-ard et al.(2010).

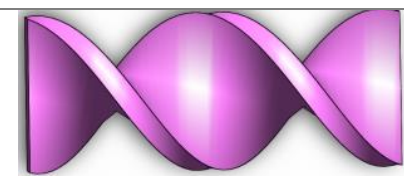

Fluid: Air

Parameters:

$3700 \leq R e_{r s} \leq 21000$

Pitch ratios 2.5,3,3.5 and 4.0

Perforated holes $\mathrm{N}=4,6$ and 8 .

Minimum and maximum values of results:

$N u_{r s}=27-188$

$f_{r s}=0.031-0.052$,

$\eta_{\rho}=1.4$.

Fluid: Air,

Parameters:

$3000 \leq R e_{r s} \leq 27000$

$\mathrm{y}_{\mathrm{rs}}=3.0,4.0$, and 5.0.

Minimum and maximum values of results:

$N u_{r s}=43-265$

$f_{r s}=0.03-0.052$,

$\eta_{\rho}=1.34$.

\section{Fluid: Air}

Parameters:

$4600 \leq R e_{r s} \leq 20000$

Two various $\mathrm{y}_{\mathrm{rs}}=3.0,4.0$

of TT of varying three coils pitch ratios.

Minimum and maximum values

$N u_{r s}=15-148$

$f_{r s}=0.032-0.053$,

$\eta_{\rho}=1.1-1.25$.

\section{Fluid: Air}

Parameters:

$3000 \leq R e_{r s} \leq 27000$

$\mathrm{y}_{\mathrm{rs}}=3.0,4.0$ and 5.0.

$\left(d_{r s} / w_{r s}\right.$ is Depth ratio $)=$

$0.11, .021$ and 0.32 .

Minimum and maximum values

$N u_{r s}=27-274$

of

$f_{r s}=0.05-0.31$

$\eta_{\rho}=1.05-1.95$.

Fluid: Air, Parameters: $4000 \leq R e_{r s} \leq 19000$

Minimum and maximum values of results:

$N u_{r s}=16-72$

$f_{r s}=0.03-0.15$,

$\eta_{\rho}=0.8-1.2$.

Fluid: Air

Parameters:

$4000 \leq \mathrm{Re}_{\mathrm{rs}} \leq 20000$ $0.29,0.43,0.57$ and 1.0 . $\mathrm{y}_{\mathrm{rs}}=3.0,4.0$, and 5.0.

Tape length ratios are
$N u_{r s}=0.4141 \times 10^{-4} \operatorname{Re}_{r S}{ }^{0.9591} \mathrm{Pr}_{r S} r^{0.4}\left[0.001\left(H_{r s} / W\right)^{-0.4655}\right]\left(D_{b} / L\right)^{-1.411}\left(D_{r s}\right)=$ hydraulic diameter, and $H_{r s}{ }^{\prime}$ is pitch $)$ $f_{r s}=0.0139 R e^{-0.1374}\left[\left(0.001+H_{r s} / W\right)^{-0.001}\right]\left(D_{b} / L\right)^{-0.2097}$.

$N u_{r s}=0.473 R e_{r s}{ }^{0.66} \operatorname{Pr}_{r s}{ }^{0.4}\left(y_{r s} / w\right)^{-0.9}$ and

$f_{r s}=72.29 R e_{r s}{ }^{-0.53}\left(y_{r s} / w\right)^{-1.01}($ twin counter TT)

$N u_{r s}=0.264 R e_{r s}{ }^{0.66} \operatorname{Pr}_{r s}{ }^{0.4}\left(y_{r s} / w\right)^{-0.61}$ and

$f_{r s}=41.7 R e_{r s}{ }^{-0.52}\left(y_{r s} / w\right)^{-0.84}($ For twin co-TT)

$\eta_{r s}=1.84 R e_{r s}{ }^{-0.186}\left(y_{r s} / w\right)^{-0.038}$

$N u_{r s}=0.31 R e_{r s}{ }^{0.6} \operatorname{Pr}_{r s}{ }^{0.4}\left(y_{r s} / w\right)^{-0.36}(1+\sin \theta)^{0.44}$

$f_{r s}=46.39 R e_{r s}{ }^{-0.544}\left(y_{r s} / w\right)^{-0.77}(1+\sin \theta)^{0.45}$

$\eta_{r s}=2.93 R e_{r s}{ }^{-0.01}\left(y_{r s} / w\right)^{-0.77}(1+\sin \theta)^{0.31}$.

$N u_{r S}=0.197 R e_{r S}{ }^{0.708} P r_{r S}{ }^{0.4}(1+\mathrm{S})^{-0.244}$

(Decrease coil pitch ratios and

TT)

$N u_{r s}=0.186 R e_{r s}{ }^{0.713} \operatorname{Pr}_{r s}{ }^{0.4}(1+\mathrm{S})^{-0.249}$

(Decreasing/increasing coil pitch ratios and TT) $f_{r s}=12.133 R e_{r s}{ }^{-0.232} Y_{r s}{ }^{-0.302} \mathrm{f}_{\mathrm{rs}}=22.366 R e_{r s}{ }^{-0.277} Y_{r s}{ }^{-0.449}$.

$N u_{r s}=0.18 R e_{r s}{ }^{0.67} \operatorname{Pr}_{r s}{ }^{0.4}\left(y_{r s} / w\right)^{-0.424}(1+d / w)^{0.982} \quad$ (For oblique delta-winglet TT) $N u_{r s}=0.184 R e_{r s}{ }^{0.67} P r_{r s}{ }^{0.4}\left(y_{r s} / w\right)^{-0.465}(1+d / w)^{0.76}($ Strai ght D-W TT) $f_{r s}=24.8 R e_{r s}{ }^{-0.51}\left(y_{r s} / w\right)^{-0.566}(1+d / w)^{1.87}$ (Oblique D-W TT)

$f_{r s}=21.7 \operatorname{Re}_{\mathrm{rs}}{ }^{-0.45}\left(y_{r s} / w\right)^{-0.564}(1+d / w)^{-1.41}$

$\eta_{r s}=2.046 R e_{r s}{ }^{-0.042} \operatorname{Pr}_{r s}{ }^{0.4}\left(y_{r s} / w\right)^{-0.0261}(1+\mathrm{d} / \mathrm{w})^{0.45}$

$\eta_{r s}=2.1646 R e_{r s}{ }^{-0.0435} \operatorname{Pr}_{r s}{ }^{0.4}\left(y_{r s} / w\right)^{-0.0304}(1+d / w)^{0.356}$.

$N u_{r s}=0.06 \operatorname{Re}^{0.75} \operatorname{Pr}^{0.4}\left(y_{r s} / W\right)^{-0.26}$

(For single $\quad$ TT inserts)

$N u_{r s}=0.069 R e_{r s}{ }^{0.74} P r_{r s}{ }^{0.4}\left(y_{r s} / W\right)^{-0.26}\left[1.5\left(s / D_{r s}\right)+1\right]^{-0.1}$

(For dual TT inserts)

$f_{r s}=10.02 R e_{r s}{ }^{-0.46}\left(y_{r s} / W\right)^{-0.48} \quad$ (For single TT inserts) $f_{r s}=30.5 R e_{r s}{ }^{-0.56}\left(y_{r s} / W\right)^{-0.54}\left[1.5\left(s / D_{r s}\right)+1\right]^{-0.2}$ (For dual TT inserts) $\eta_{r s}=2.46 R e_{r s} e^{-0.08}\left(y_{r s} / W\right)^{-0.2}$

$N u_{r s}=0.0664 R e_{r s}{ }^{0.693}\left(P r_{r s}{ }^{0.4}\right) L R^{-0.122}$

('LR' = tape -length ratios)

$f_{r s}=2.8 R e_{r s}{ }^{-0.386} L R^{0.19}$ 


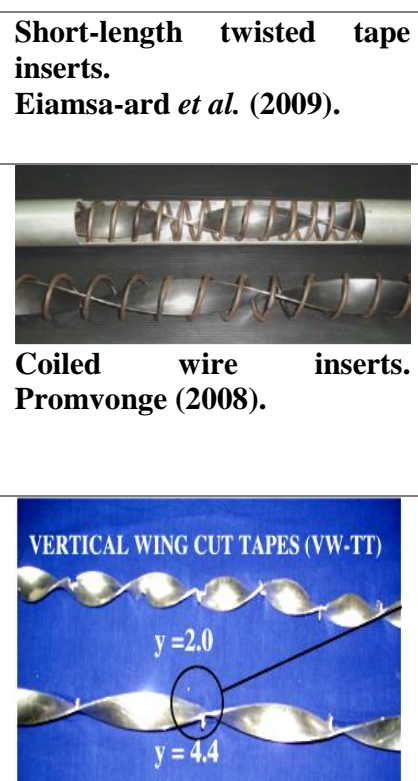

VW twisted tape. Mazumder and Saha (2008).

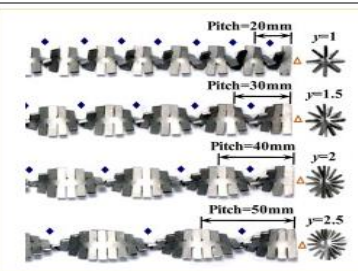

Broken twisted tape inserts. Chang et al. (2007).

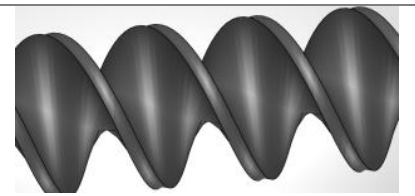

Twisted tape inserts. Chang et al. (2007).

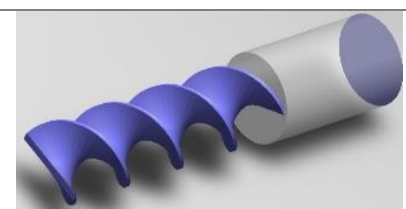

Circular tube inserted with classical TT. Eiamsa-ard, et al. (2006).

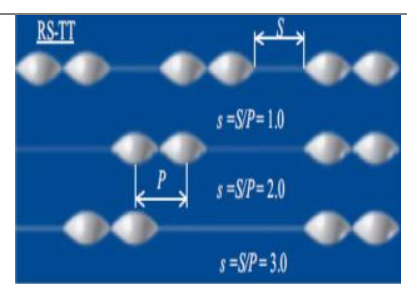

Regularly spaced twisted tape inserts. Eiamsa-ard et al. (2006).

Minimum and maximum

values of $\mathrm{Nu}_{\mathrm{rs}}=12-58$

$\mathrm{f}_{\mathrm{rs}} 0.03-0.05=$,

$\eta_{\rho}=0.9-1.17$

Fluid: Air, Parameters: $N u_{r s}=4.47 R e_{r s}{ }^{0.5}\left(\operatorname{Pr}_{r s}{ }^{0.4}\right) C R^{-0.382} Y_{r s}{ }^{-0.38}$ and $3000 \leq R e_{r s} \leq 18000$

Pitch ratios e 4.0, 6.0 and 8.0. $\mathrm{y}_{\mathrm{rs}}=4.0, \quad 6.0$. Minimum and maximum values of results:

$N u_{r s}=12-174$

$f_{r s}=0.5-3.0$,

$\eta_{\rho}=0.5-1.57$.

\section{Fluid: Air}

Parameters:

$11543 \leq R e_{r s} \leq 108166$

$\mathrm{y}_{\mathrm{rs}}=2.0,4.4$

Minimum and maximum

values of results:

$N u_{r s}=52-125$

$f_{r s}=0.5-0.9$,

$\eta_{\rho}=1.3-1.7$.

$$
\begin{aligned}
& N u_{r s}=4.47 R e_{r s}{ }^{-0.367} C R^{-0.887} Y_{r s}{ }^{-0.4660} \\
& f_{r s}=338.37 R e_{r s}
\end{aligned}
$$

(Regular spaced TT)

$N u_{r s}=0.023($ Term $1+$ Term 2$)(1 / A R+0.1)^{0.15} \frac{\left(e / D_{r s}\right)^{0.0541} I^{0.182}}{(p / e)^{0.754}}$

$(A R \leq 1)$

$\left(\right.$ Short length TT)Nurs $=0.023($ Term $1+$ Term 2$)(1 / A R+0.1)^{0.15} \frac{\left(e / D_{r s}\right)^{0.01561 \frac{d}{0.122}^{0.120}}}{(p / e)^{0.136}}$

$K\left\{1+10^{-6}\left[\left(\frac{R e_{r s}{ }^{2}}{Y_{r s}}\right)\left(\frac{\pi}{\pi-\left(\frac{4 s}{D_{r s}}\right)}\right)\left[1+\left(\pi / 2 Y_{r S}\right)^{2}\right]^{0.5}\right]^{2.67}\right\}^{\frac{1}{7}} \frac{\left(e / D_{r s}\right)^{0.0343} I^{0.178}}{(p / e)^{0.739}(A R)^{1.52}}$

Fluid: Air,

Parameters:

$1000 \leq R e_{r s} \leq 40000$,

$y_{r s}=1.0,1.5$,

2.0 , and 2.5 , twist ratios y

$=1,1.5,2$, and $\mathrm{y}=2.5$.

Minimum and maximum values of results:

$N u_{r s}=50-350$

$f_{r s}=0.12-0.25$,

$\eta_{\rho}=0.98-1.28$.

Fluid: Air

Parameters:

$5000 \leq R e_{r s} \leq 25000$,

$y_{r s}=1.56,1.87,2.82$.

Minimum and maximum

values

$N u_{r s}=62-280$

$f_{r s}=0.3-0.48$,

$\eta_{\rho}=0.9-1.4$.

Fluid: Air

Parameters:

$5000 \leq R e_{r s} \leq 15000$,

$y_{r s}=6.0,8.0$ and space ratio of 1.0,2.0,3.0.

Minimum and maximum values of results: $N u_{r s}=10-87$,

$f_{r s}=0.1-0.24$.

Fluid: Air

Parameters:

$5000 \leq R e_{r s} \leq 20000$

$\mathrm{y}_{\mathrm{rs}}=6.0,8.0$.

Space ratios are 1.0, 2.0

3.0.

Minimum and maximum values of results:

$N u_{r s}=10-90$

$f_{r s}=0.05-0.24$,

$\eta_{\rho}=1.2-1.76$.
$N u_{r s}=P r_{r s}{ }^{\frac{1}{3}} R e_{r s}\left[A\{y\}+B\{y\} e^{-C\{y\}^{X}}\right]$

$X$ is dimensionless axial location

$A=0.04520+0.30 e^{-0.1410 y}, B=0.0410+1.280 e^{-1.490 y}$

$f_{r s}=-E(y)-K(y) e^{-M[y] R e}$,

$E=0.01740+0.2160 e^{-1.207 y}, K=0.020+0.1610 e^{-1.207 y} M=0.000340-0.0003210 e^{-0.548 y}$.
$N u_{r s}=0.144 R e_{r s}{ }^{0.697} \operatorname{Pr}_{\mathrm{rs}}{ }^{0.4}(s+1)^{-0.179}$

$f_{r s}=3.044 R e_{r s}{ }^{-0.80} y^{-0.0556}(s+1)^{-0.34}$ and

$\eta_{r s}=3.854 R e_{r s}^{-0.151} y^{-0.043}(s+1)^{-0.065}$
$N u_{r s}=0.0101 R e_{r S}{ }^{0.929} \operatorname{Pr}_{r s}{ }^{\frac{1}{3}}(1+S)^{-0.266}(\mathrm{~S}=$ Free Space Ratio $)$ $f_{r s}=4.413 R e_{r s}{ }^{-0.398}(1+S)^{-0.376}$ 


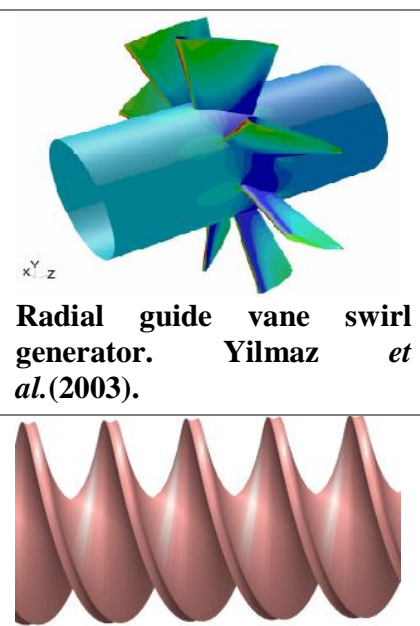

Square duct with twisted tape inserts. Ray and Date (2001).

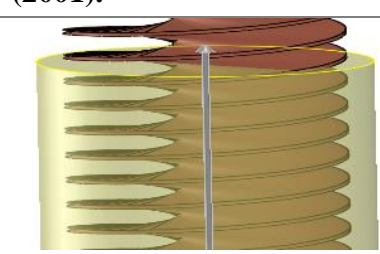

Vertical pipe with twisted tape. Klaczak, A.(2000).

Twisted tape geometry Working fluid: Water

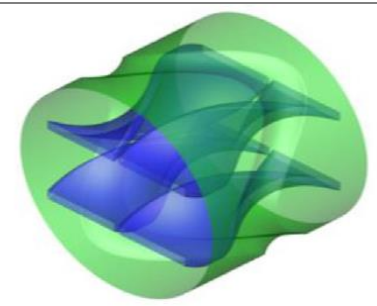

SRT-4 twisted tapes insert. Hong et al. (2019).

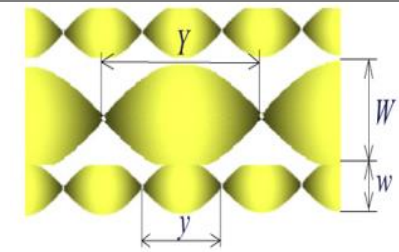

Multiple- twisted tapes. Piriyarungrod et al. (2018).

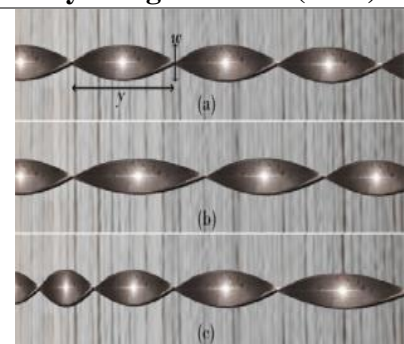

Typical twisted tape inserts. Maddah et al. (2014).
Fluid: Air

Parameters:

$200 \leq R e_{r s} \leq 11000$

Angular vane angle $\left(\theta_{r s}\right)$

$=15^{\circ}, 30^{\circ}, 45^{\circ}, 60^{\circ}$ and $75^{\circ}$.

Minimum and maximum values of results: $N u_{r s}=67-392$

$f_{r s}=3.5-16.8, \eta_{\rho}=$ 1.67.

Fluid: Air

Parameters:

$30 \leq R e_{r s} \leq 11,00$

$\mathrm{y}_{\mathrm{rs}}=1.5$ to 10 ,

$\mathrm{Pr}_{\mathrm{rs}}=0.1$ to 500 .

Minimum and maximum values of results:

$N u_{r s}=5-120$

$f_{r s}=0.3-1.2$.

\section{Fluid: Air}

Parameters:

$110 \leq R e_{r s} \leq 1500$

$\mathrm{y}_{\mathrm{rs}}=1.63$ to 5.28 .

$\mathrm{G}_{\mathrm{rs}}=8.1-82.0$.

Minimum and maximum

values of results:

$N u_{r s}=3.0-10$.
$N u_{r s}=0.133 R e_{r s}{ }^{0.65}\left(P r_{r s}\right)^{0.4}(1+\tan \theta)^{0.405}$

( swirl generator with conical deflection)

$N u_{r s}=0.313 R e_{r s}{ }^{0.360}\left(P r_{r s}\right)^{0.40}(1+\tan \theta)^{0.3970}$

( swirl generator with spherical defelection)

$N u_{r s}=0.368 R e_{r s}{ }^{0.562}\left(P r_{r s}\right)^{0.40}(1+\tan \theta)^{0.459}$.

(swirl generator with nil deflection)
$N u_{r s}=3.96\left[1+1.6 \times 10^{-2} P r_{r s}{ }^{1.05}\left(\frac{R e_{r s}}{Y}\right)^{1.25}\right]^{\frac{1}{26}} S w_{S}{ }^{\prime}$ is notational swirl parameter $\quad S w_{S}=\left(\frac{R e_{r s}}{Y}\right)^{\frac{1}{4}}\left[\frac{1+0.01 Y^{4}}{Y^{8}}\right]^{\frac{1}{4}}$, $f_{r s}=36 R e_{r s}\left[1+0.15 S_{w}\right]^{1 / 1.3}$

$$
\begin{aligned}
& N u_{r s}=1.239 G z^{\left(0.514 y_{r s}{ }^{-0.27}\right) y_{r s}{ }^{0.30}} \\
& \left(\text { For } 8.1 \leq G z \leq 82,58 \leq S w \leq 1900,2.06 \leq P r_{r s} \leq 2.73\right) \\
& N u_{r s}=0.858 P r_{r s}{ }^{0.3} S w^{0.3}\left(\frac{\eta_{a r}}{\eta_{w}}\right)^{0.14}
\end{aligned}
$$

Parameters/optimum ranges
Fluid: Water

Parameters:

$5000 \leq \operatorname{Re}_{\mathrm{rs}} \leq 10000$

Rib pitch to diameter ratios at $0.27-1.53$, rib height to diameter ratios at $0.02-0.056$ and corrugation angles at $9.2^{\circ}-37.0^{\circ}$

$N u_{r s}=27.4 \%-39.5 \%$

$f_{r s}=2.66-10.07$,

$\eta_{\rho}=1.59$ and 1.49 .

Fluid: Water

Parameters:

$6000 \leq R e_{r s} \leq 20000$

$(\mathrm{y} / \mathrm{w}=2.5,5,10,15,20$ and 25)

$N u_{r s}=1.13,1.18$, and 1.2

$f_{r s}=0.14-0.20$

$\eta_{\rho}=1.2$.

Fluid: Water/ Nanofluid

Parameters:

$5000 \leq R e_{r s} \leq 21000$

$\mathrm{y}_{\mathrm{rs}}=1.03$ to 4 .

Minimum and maximum

values of results:

$N u_{r s}=50-210$

$f_{r s}=0.04-0.075$,

$\eta_{\rho}=1.3-1.89$.

$$
\begin{aligned}
& N u_{r s}=\frac{\left(\frac{f}{8}\right)(R e-1000) \operatorname{Pr}}{1+12.7\left(\frac{f}{8}\right)^{\frac{1}{2}}\left(\operatorname{Pr}^{\frac{2}{3}}-1\right)} \\
& f_{r s}=0.136 R e_{r s}-0.25
\end{aligned}
$$

$f_{r s}=2.9134 R e_{r s}{ }^{-0.065}\left(\frac{e}{d}\right)^{0.972}\left(\frac{p}{d}\right)^{-0.313}\left[\frac{90^{0}-\varnothing}{90^{0}}\right]^{1.004}$

$N u_{r s}=0.056 \operatorname{Re}_{\mathrm{rs}}{ }^{0.72}\left(P r_{r s}\right)^{0.4}\left(\pi \phi_{\mathrm{rs}}+1\right)^{2.75}\left(1+\frac{\pi}{2 T R}\right)^{1.1} G P R^{-0.75}$
(' $\phi_{\mathrm{rs}}, \quad$ volume concentration, $\quad{ }_{\text {TR: }} \quad$ Twist
Ratio $) f_{r s}=0.375 \operatorname{Re}_{\mathrm{rs}}{ }^{-0.24}\left(1+3 \pi \phi_{\mathrm{rs}}\right)^{0.6}\left(1+\frac{\pi}{T R^{1.4}}\right) G P R^{-0.35}$




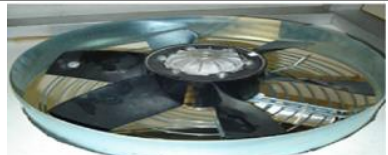

Schematic diagram of Classic twisted tape. Karami et al. (2012).

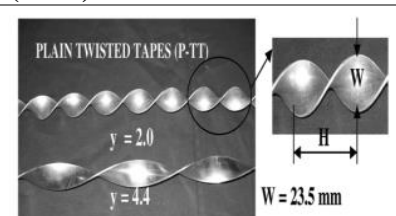

Geometries of twisted tapes. Murugesan et al. (2012).

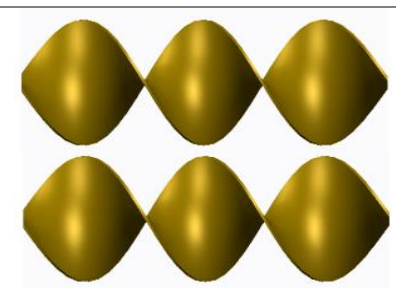

Tubes equipped with twin twisted tapes. Zhang et al. (2012).

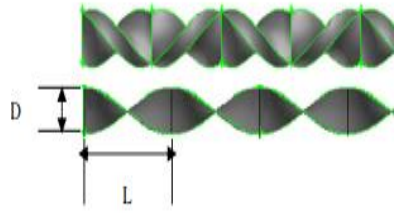

Left-Right various spacer length tape. Jaisankar et al. (2011).

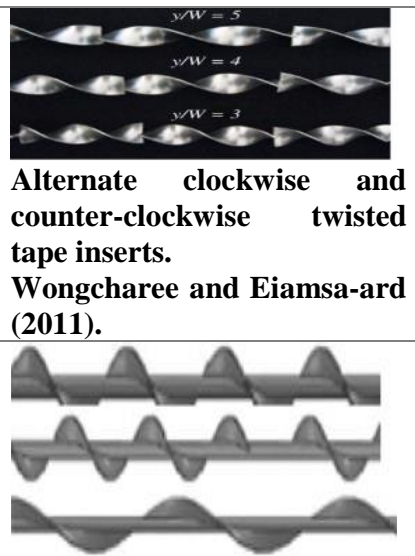

Helical screw-tape. Ibrahim (2011).

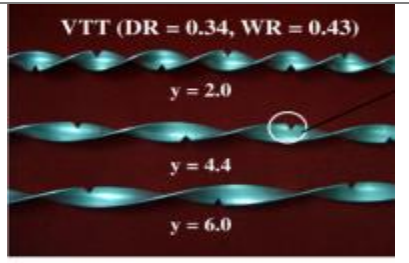

V-cut Twisted tapes inserts. Murugesan et al. (2011).
Fluid: Water, Parameters:

$4021 \leq R e_{r s} \leq 16,118$

(y/w $=1.76$ to 3.53$)$

$N u_{r s}=147.827$

$\eta_{\rho}=1.76$.
$N u_{r s}=90.2+14.7 R e-3.72 R e-0.276 R e^{2}-0.539 R e \times R$

Fluid

Water, $\quad N u_{r s}=0.027 e^{0.8620} P r_{r s}{ }^{0.33} Y_{r s}{ }^{-0.215}$ and

Parameters:

$2000 \leq R e_{r s} \leq 12000$

$\mathrm{y}_{\mathrm{rs}}=2.0,4.4$ and 6.0.

Minimum and maximum

values of results:

$N u_{r s}=18-130$

$f_{r s}=0.03-0.29$,

$\eta_{\rho}=1.05-1.5$.

Fluid: Water

Parameters:

$300 \leq \operatorname{Re}_{\mathrm{rs}} \leq 1800$

Helical screw breadth is

$7.50,120, \quad 150$ and

$200 \mathrm{~mm}$.

Minimum and maximum values of results:

$N u_{r s}=8.2-13.5$

$f_{r s}=0.2-1.3$,

$\eta_{\rho}=1.6-2.3$.

Fluid: Water

Parameters:

$200 \leq \operatorname{Re}_{\mathrm{rs}} \leq 1600$

$y_{r s}=3.0, \quad 5.0$ spacer

length(mm) 100, 200, 300.

Minimum and maximum values of results:

$f_{r s}=2.642 R e_{r s}{ }^{-0.474} Y_{r s}{ }^{-0.302}$

$\left.N u_{r s}=0.128 R e_{r s}{ }^{0.723} \operatorname{Pr}_{r s}{ }^{0.4}\left(e_{p}\right)^{-0.188}\left(e_{w}\right)^{0.318}\right)$

,Nu $u_{r s}=0.139 R e_{r s}{ }^{0.723} \mathrm{Pr}_{r s}{ }^{0.4}\left(e_{p}\right)^{-0.198}\left(e_{w}\right)^{0.339}$

$N u_{r s}=2.0358 R e_{r s}{ }^{0.2380}\left(\alpha^{*}\right)^{0.0492}(\mathrm{TTT})$,

(

" $\alpha$ " clearance ratio of the TT) $N u_{r s}=1.5689 R e_{r s}{ }^{0.2629}\left(\alpha^{*}\right)^{-0.0773}$

(Quadruple TT), $\quad f_{r s}=1.09 R e_{r s}{ }^{-0.098}\left(e_{p}\right)^{-0.198}\left(e_{w}\right)^{0.547}$,

$f_{r s}=1.680 R e_{r s}{ }^{-0.127}\left(e_{p}\right)^{-0.198}\left(e_{w}\right)^{0.636}$

$f_{r s}=111.2919 R e_{r s}{ }^{-0.7236}$

(For phase 1)

$N u_{r s}=0.783 R e_{r s}{ }^{0.44} \operatorname{Pr}_{r s}{ }^{0.589} Y_{r s}{ }^{.305}\left(1+S / D_{r s}\right)^{-0.124}$ and

$f_{r s}=1212.69 R e_{r s}{ }^{-0.904} Y_{r s}{ }^{-0.955}\left(1+S / D_{r s}\right)^{-0.0515}$

(For phase 2)

$N u_{r s}=0.617 R e_{r s}{ }^{0574} \mathrm{Pr}_{r s}{ }^{0.574} Y_{r s}{ }^{309}\left(1+S / D_{r s}\right)^{-0.129}$ and

$f_{r s}=13.11 .69 R e_{r s}{ }^{-0.904} y_{r s}{ }^{-0.955}\left(1+S / D_{r s}\right)^{-0.374}$.

$N u_{r s}=4.0-23$

$f_{r s}=0.03-0.09$

$\eta_{\rho}=1.21-1.41$.

Fluid: Water

Parameters:

$830 \leq R e_{r s} \leq 1990, \mathrm{y}_{\mathrm{rs}}=$

3.0, 4.0 and 5.0.

Minimum and maximum

values of results:

$N u_{r s}=11-64$

$f_{r s}=0.25-0.62$,

$\eta_{\rho}=2.2-5.4$.

Fluid: Water

Parameters:

$570 \leq \operatorname{Re}_{\mathrm{rs}} \leq 1310, \quad \mathrm{y}_{\mathrm{rs}}$

$=2.17,3.33,4.3$ and 5.0.

Spacer lengths of 100,

200, 300, and $400 \mathrm{~mm}$.

$\mathrm{Nu}_{\mathrm{rs}}=9-21$,

$f_{r s}=0.04-0.18$.

Fluid: Water

Parameters:

$2000 \leq R e_{r s} \leq 12000$

$\mathrm{y}_{\mathrm{rs}}=2.0,4.4$ and 6.0 .

width ratio $=0.34$ and $N u_{r s}=0.0017 R e_{r s}{ }^{0.996} \mathrm{Pr}_{r s} Y_{r s}{ }^{-0.5437}$ and $f_{r s}=10.7564 R e_{r s}{ }^{-0.387} Y_{r s}{ }^{-1.054}$.
$N u_{r s}=6.11 R e_{r s}{ }^{0.199}(1+x)^{-0.064} Y_{r s}{ }^{-0.3118} \quad$ and $f_{r S}=54.41 R e_{r s}{ }^{-0.87}(1+x)^{-0.045} Y_{r s}{ }^{-0.146}$ or tubes fitted withv - cut TT)

$f_{r s}=8.632 R e_{r s}{ }^{-0.615} y_{r s}{ }^{-0.269}\left(1+\left[d_{e} / w\right]^{2.477}\right)\left[1+[w / W]^{-1.914}\right]$

0.43

Minimum and maximum values of results:

$N u_{r s}=20-128$

$f_{r s}=0.08-0.29$,

$\eta_{\rho}=1.02-1.29$ 


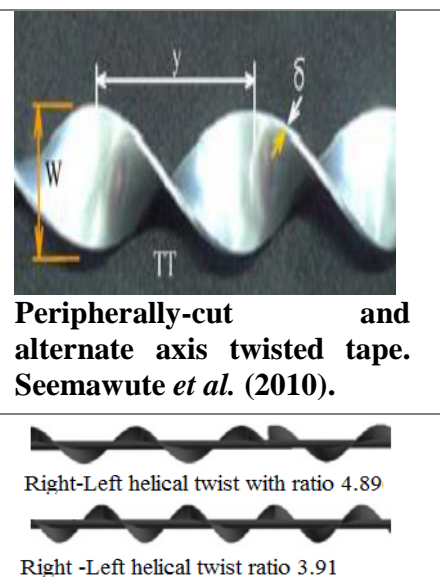

TT with left- right - helical screw.

Nagarajan et al. (2010).

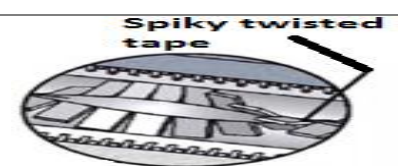

Spiky twisted tapes. Chang et al (2009).

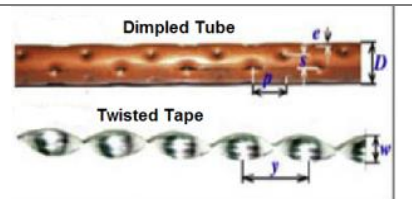

Dimple tube with twisted tape inserts. Thianpong et al. (2009).

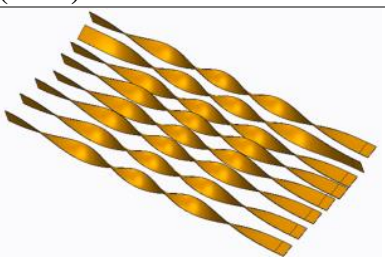

Twisted tape inserts. Sharma et al. (2009).

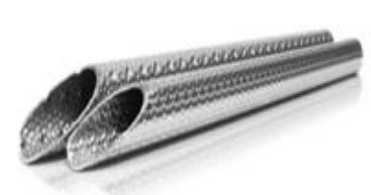

Dimple tube fitted with twisted tape inserts. Bharadwaj et al. (2009).

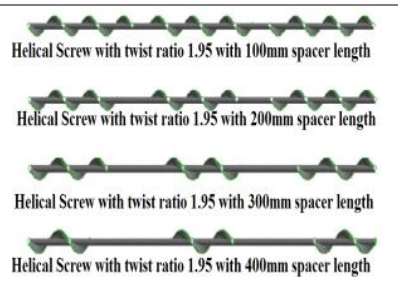

Helical screw twisted tape inserts. Sivashanmugam and Suresh (2007).
Fluid: Water

Parameters:

$5000 \leq R e_{r s} \leq 20000$

Peripherally- cut TT with alternate axis $1.25,1.11$ and 1.02.

Minimum and maximum values

$N u_{r s}=45-275$

$f_{r s}=0.12-0.5$,

$\eta_{\rho}=1.05-1.25$

Fluid: Water

Parameters:

$200 \leq R e_{r s} \leq 3000$

$y_{\text {rs }}=2.93$ to 4.89

Minimum and maximum

values of results:

$N u_{r s}=38192$

$f_{r s}=0.02-0.25$,

$\eta_{\rho}=1.2-1.83$

Fluid: Water, Parameters:

$5000 \leq \mathrm{Re}_{\mathrm{rs}} \leq 15000$

Stream ratio 0.004 to 0.01

Minimum and maximum

values of results:

$N u_{r s}=40-510$

$f_{r s}=0.5-1.6$,

$\eta_{\rho}=1.2-4.1$.

Fluid: Water

Parameters:

$12000 \leq \mathrm{Re}_{\mathrm{rs}} \leq 44000$

$\mathrm{y}_{\mathrm{rs}}=3.0,5.0$, and 7.0

Minimum and maximum

values of results:

$N u_{r s}=55-457$

$f_{r s}=0.06-0.24$

Fluid: Water

Parameters:

$3500 \leq R e_{r s} \leq 8500$

$0 \leq H / D \leq 15$,

$4.5 \leq \operatorname{Pr} \leq 5.5$

Minimum and maximum values of results:

$N u_{r s}=30-90$

$f_{r s}=0.04-0.09$,

$\eta_{\rho}=1.2-1.4$.

Fluid: Water

Parameters:

$12000 \leq R e_{r s} \leq 44000$

$y_{r s}=3.0,5.0$, and 7.0.

Minimum and maximum

values of results:

$N u_{r s}=20-160$

$f_{r s}=0.01-0.13$

$\eta_{\rho}=0.9-1.48$.

Fluid: Water

Parameters:

$2700 \leq \mathrm{Re}_{\mathrm{rs}} \leq 13500$

$y_{r s}=1.95,2.93,3.91 \&$

4.89. Spacer length 100 ,

200, 300 and $400 \mathrm{~mm}$.

Minimum and maximum values of results:

$N u_{r s}=40-155$

$f_{r s}=0.07-0.11, \eta_{\rho}=$

$$
\begin{aligned}
& N u_{r s}=0.422 R e_{r s}{ }^{0.544} \operatorname{Pr}_{r s}{ }^{0.4}\left(\frac{w}{W}\right)^{-0.148} \\
& f_{r s}=59.08 R e_{r s}{ }^{-0.615}\left(\frac{w}{W}\right)^{-0.18}
\end{aligned}
$$$$
N u_{r s}=0.3962(Y)^{-0.3866} P r_{r s}^{0.3}\left(R e_{r s}\right)^{0.6717}\left(P r_{r s}\right)^{0.4}
$$$$
\left(\frac{\mu}{\mu^{w}}\right)^{0.14}
$$$$
N u_{r s}=2.81\left(Y_{L-R}\right)^{-0.3966} P r_{r s}{ }^{0.3}\left(R e_{r s}\right)^{0.478}\left(P r_{r s}\right)^{0.4}\left(\mu / \mu_{w}\right)^{0.14}
$$$$
f_{r s}=739.2\left(Y_{r s}\right)^{-0.634}\left(R e_{r s}\right)^{-1.013}\left(y_{r s} / w\right)^{-0.2}
$$

$$
N_{r s}=\left(0.323+0.1366 \times e^{-1164 \times A W}\right) \times R e_{r s}
$$
$0.79-0.135 \times e^{-1074 \times A W}$

$$
\begin{aligned}
& N u_{r s}=0.014 R e^{0.93}\left(R e_{r s}\right)^{-0.93}\left(\frac{y_{r s}}{w}\right)^{-0.12} \operatorname{Pr}_{r s}{ }^{0.3} \\
& f_{r s}=9.1 R e_{r s}{ }^{-0.37}\left(R e_{r s}\right)^{-0.11}\left(\frac{y_{r s}}{w}\right)^{-0.2}
\end{aligned}
$$

$N u_{r s}=3.138 * 10^{-3}\left(\operatorname{Re}_{\mathrm{rs}}\right)\left(P r_{r s}\right)^{0.6}\left(1.0+H_{r s} / D_{r s}\right)^{0.03}(\phi+1)^{1.22}$ $\left(0<\mathrm{H}_{\mathrm{rs}} / \mathrm{D}_{\mathrm{rs}}<15,3500<R e_{r s}<8500,4.5<P r_{r s}<5.5,35<\mathrm{Tb}<\right.$ 40)

$f_{r s}=173\left(R e_{r s}\right)^{-0.96}\left(1.0+H_{r s} / D_{r s}\right)^{2.15}(\phi+1)^{2.15}$

(For $\mathrm{Y}_{\mathrm{rs}}=10.16, R e_{r s}<7000$, Clockwise twist)

$N u_{r s}=0.1949 R e_{r s}{ }^{0.71145}, N u_{r s}=0.6916 R e_{r s}{ }^{0.535}$

$N u_{r s}=0.02564 R e_{r s} 0.93750$

$N u_{r s}=0.01887 R e_{r s}{ }^{0.9724}, f_{r s}=15.88 R e_{r s}{ }^{-0.75975}$

$f_{r s}=8.029 R e_{r s}{ }^{-0.6367}, f_{r s}=0.021 R e_{r s}{ }^{-0.0}$

$f_{r s}=0.061 R e_{r s}-0.1015{ }^{,}$

$$
\begin{aligned}
& N u_{r s}=0.258 R e_{r s}{ }^{0.554}\left(P r_{r s}\right)\left(Y_{r s}\right)^{-0.042}\left(1+s / D_{r s}\right)^{-0.042} \text { and } \\
& f_{r s}=R e_{r s}{ }^{-0.384} Y_{r s}{ }^{-0.852}\left(1+s / D_{r s}\right)^{-0.047}
\end{aligned}
$$




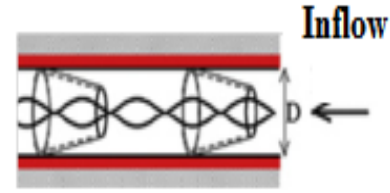

Twisted tape inserts with conical-ring. Promvonge et al. (2007).

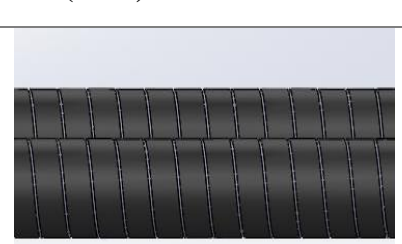

Horizontal pipe with helical ribs. Naphon et al. (2006).

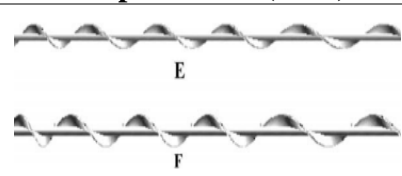

Twisted tapes with different twist ratios. Sivashanmugam \& Suresh (2006).

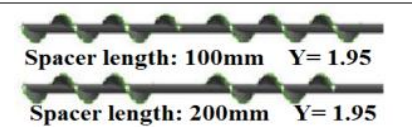

Helical screw tape. ivashanmugam et al. (2006).

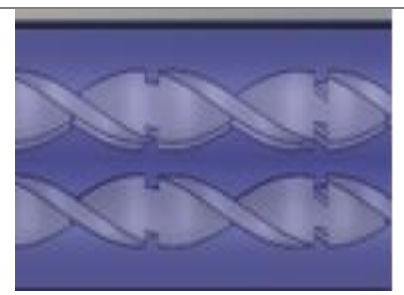

Regularly spaced twisted tape inserts. Saha et al. ( 2004).

Twisted tape geometry Working fluid: Oil

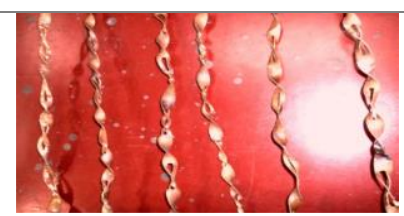

Circular with center-cleared twisted tapes.Saha et al. (2012).
Fluid: Water

$6000 \leq R e_{r s} \leq 26000$

$\mathrm{y}_{\mathrm{rs}}=3.75$ and 7.5.

Minimum and maximum values of results:

$N u_{r s}=125-223$

$f_{r s}=4-6.1$,

$\eta_{\rho}=1.2-1.9$.

Fluid: Water,Parameters:

$15000 \leq R e_{r s} \leq 60000$

$\mathrm{y}_{\mathrm{rs}}=3.1-5.5$

Minimum and maximum

values of results:

$N u_{r s}=40-110$

$f_{r s}=1.0-1.6$,

$\alpha=2.5-6.6$.

Fluid: Water

Parameters:

$2700 \leq \mathrm{Re}_{\mathrm{rs}} \leq 13500$

$\mathrm{y}_{\mathrm{rs}}=1.95,2.93,3.91$ and

4.89 .

Minimum and maximum

values of results:

$N u_{r s}=11-80$

$f_{r s}=0.1-0.6$

Fluid: Water

Parameters:

$200 \leq R e_{r s} \leq 3000$

Minimum and maximum

values of results:

$N u_{r s}=10-70$

$f_{r s}=0.1-0.55$,

$\eta_{\rho}=1.3-1.82$.

Fluid: Water

Parameters:

$80 \leq \operatorname{Re}_{\mathrm{rs}} \leq 500$

$\mathrm{y}_{\mathrm{rs}}=2.692$ to 4.615 ,

Aspect ratio $=1,0.5$,

$0.333, \mathrm{Pr}_{\mathrm{rs}}=80$ to 500 .

Minimum and maximum

values

results: $N u_{r s}=6-150.5$

$f_{r s}=0.5-1.0, \eta_{\rho}=1.0$ -

1.32 .

Parameters/optimum

ranges

Fluid: Oil

Parameters: Rib Pitch: 2.0437, 5.6481, Rib

Height $=0.07692,0.1026$.

Centre clearance $=0,0.2$,

$0.4,0.6$

Minimum and maximum

values

results:

$N u_{r s}=0.022-1.2$

$f_{r s}=30-165$,

$\eta_{\rho}=1.2-1.48$.

$$
\begin{aligned}
& N u_{r s}=1.365 R e_{r s}{ }^{0.433} P r_{r s}{ }^{0.40}\left(d_{r s} / D_{r S}\right)^{-1.230} Y_{r s}{ }^{-0.0530} \quad \text { and } \\
& f_{r s}=24.870 R e_{r s}{ }^{-0.430}\left(d_{r s} / D_{r s}\right)^{-3.990} y_{r s}{ }^{-0.160}
\end{aligned}
$$

$$
\begin{aligned}
& N u_{r s}=0.648 R e_{r s}^{0.36}\left[1+\frac{D}{R}\right]^{0.245}\left(P r_{r s}\right)^{1 / 3} \text { for } P r_{r s}>3 \quad \text { and } \\
& f_{r s}=3.517 \operatorname{Re}_{\mathrm{rs}}{ }^{-0.414}\left[1+\frac{D}{H}\right]^{1.045}
\end{aligned}
$$

$N u_{r s}=0.467 R e_{r s}{ }^{0.4774} \operatorname{Pr}_{r s} . Y_{r s}{ }^{-0.053}$ and

$f_{r s}=32.415 R e_{r s}{ }^{-0.598} Y_{r s}{ }^{-0.7986}$

$$
\begin{aligned}
& N u_{r s}=0.725\left(\operatorname{Re}_{\mathrm{rs}}\right)^{0.568}\left(\mathrm{y}_{\mathrm{rs}}\right)^{-0.788}\left(\operatorname{Pr}_{\mathrm{rs}}\right)^{1 / 3}\left(\mu_{b} / \mu_{w}\right)^{0.14} \text { (heating) } \\
& N u_{r s}=1.365\left(\operatorname{Re}_{\mathrm{rs}}\right)^{0.517}\left(\mathrm{y}_{\mathrm{rs}}\right)^{-1.05}\left(\operatorname{Pr}_{\mathrm{rs}}\right)^{1 / 3}\left(\mu_{b} / \mu_{w}\right)^{0.14} \text { (cooling) }
\end{aligned}
$$

$$
\begin{aligned}
& N u_{r s}=5.172\left\{\left[\begin{array}{c}
\left(1+0.08932 G z^{0.9125}\right)^{2.5}+ \\
8.2273 \times 10^{-6}\left(\frac{R e_{r s}}{\sqrt{y_{r s}}} \cdot P^{0.565}\right)^{2.655} \\
+1.5638 \times 10^{-15}\left(R e_{r s} R a\right)^{2.18}
\end{array}\right]^{2.0}\right\}\left(\frac{\mu_{b}}{\mu_{w}}\right)^{0.14} \\
& {\left[1+(2 \theta / \pi)^{0.1346} l^{0.183} /(P / e)^{0.584}\right] \times B,} \\
& f_{r s}=45.8129\left[1+10^{-6}\left(\frac{R e_{r s}}{\sqrt{y_{r s}}}\right)^{2.67}\right]^{\frac{1}{7}}(A R)^{-1.39} \times\left[1+(2 \theta / \pi)^{0.1859} l^{0.226} /(P / e)^{0.612}\right] \times A \text {. }
\end{aligned}
$$

\section{Correlations}

$N u_{r s}=0.0032 R e_{r s}{ }^{0.986} \operatorname{Pr}_{r s}{ }^{0.4}\left(y_{r s} / W\right)^{-0.594}$

(For alternate clockwise and counter clockwise TT) $N u_{r s}=0.005 R e_{r s}{ }^{1.139} \mathrm{Pr}_{r s}{ }^{0.4}\left(y_{r s} / W\right)^{-0.521}$ (For TTT inserts) $f_{r s}=12.886 R e_{r s}^{-.304}\left(y_{r s} / W\right)^{-0.896}$

$f_{r s}=6.559 R e_{r s}{ }^{-.303}\left(y_{r s} / W\right)^{-0.674}$ (For TTT inserts) 


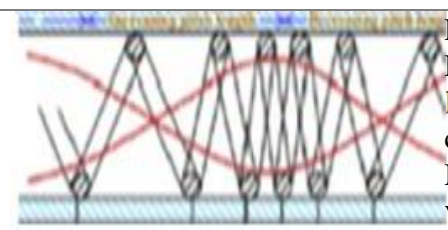

Centre-cleared twisted tape inserts. Saha (2012).
Parameters: $\mathrm{y}_{\mathrm{rs}}=2.5$ and $\mathrm{Pr}_{\mathrm{rs}}=320-$ 545. Centre clearance $=0,0.2,0.4,0.6$ Minimum and maximum values results: $N u_{r s}=5-148$, $\eta_{\rho}=0.9-1.18$.
$N u_{T S}=5.172\left[\left(\left(1+0.0798562^{0.9335}\right)^{2.5}+8.2365 \times 10^{-6}\left(S W . P_{T S} r_{T S}^{0.565}\right)^{26.55}\right)^{2.0}+1.5547 \times 10^{-15}\left(R_{T S} R a\right)^{2.18}\right] \times\left(u_{b} / \mu_{W}\right)^{0.14} \times$ $\left[1+\left(1+\exp (0.0993 c) \cdot \exp (0.0839 \sin \theta) /(P / e)^{0.095}\right]\right.$

$\left(f_{r s} R e_{r S}\right)_{s W}=17.355\left(\frac{\pi+2-2 \delta / D_{r S}}{\pi-4 \delta / D_{D_{S}}}\right)^{2}\left(1+10^{-6} S W^{2.67}\right)^{0.14} \times\left[1+(1+\exp (0.0880 \mathrm{c})) \cdot(\exp (0.04210 \sin \theta)) /(P / e)^{0.634}\right]$

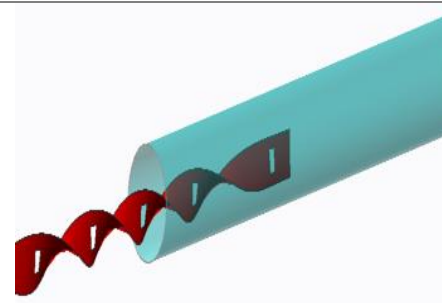

Rectangular-cut twisted tape inserts. Saha ( 2010).

\section{Fluid: Oil}

Parameters:

$175 \leq \operatorname{Re}_{\mathrm{rs}} \leq 538$

Space ratio and Aspect

ratio $=1,0.5,0.33$

Minimum and maximum

values of results: $N u_{r s}=7.3-27.7, f_{r s}=14 . f_{r s}-15.7 .355\left(\frac{\pi+2-2 \delta / D_{r s}}{\pi-4 \delta / D_{r s}}\right)^{2}$
$\quad, \eta_{\rho}=1.16-1.33$.

$$
\begin{gathered}
N u_{r s}=5.172\left\{\left[\begin{array}{c}
\left(1+0 . .89322 G z^{0.9125}\right)^{2.5}+ \\
8.2273 \times 10^{-6\left(S w . P r_{r s}{ }^{0.565}\right)^{2.655}} \\
+1.5638 \times 10^{-15\left(R e_{r s} R a\right)^{2.18}}
\end{array}\right]^{2.0}\right\}^{0.1} \\
\left(\mu_{b} / \mu_{w}\right)^{0.14}(1 / A R+0.1)^{0.15}+\left(1+\frac{(e / D)^{0.0748} l^{0.195}}{(P / e)^{0.692}}\right) \\
\left(1+10^{-6} S w^{2.67}\right)^{1 / 7} \\
(A R)^{-1.47} \times\left(1+\frac{(e / D)^{0.0654} I^{0.215}}{(P / e)^{0.587}}\right)(\text { Short length TT with internal rib) }
\end{gathered}
$$

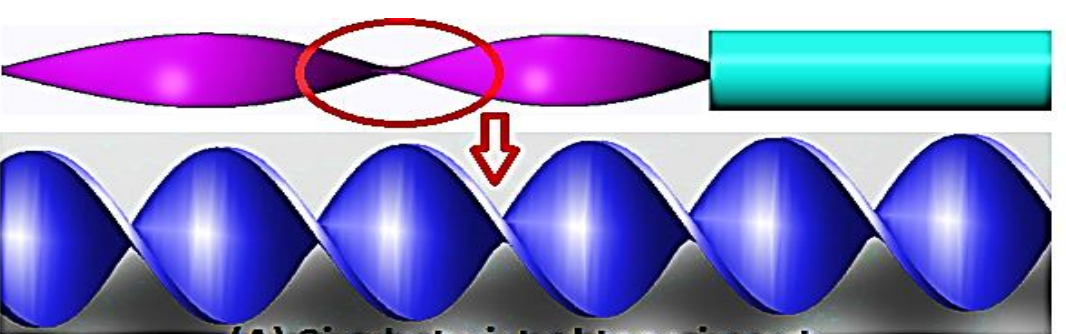

(A) Single twisted tape insert

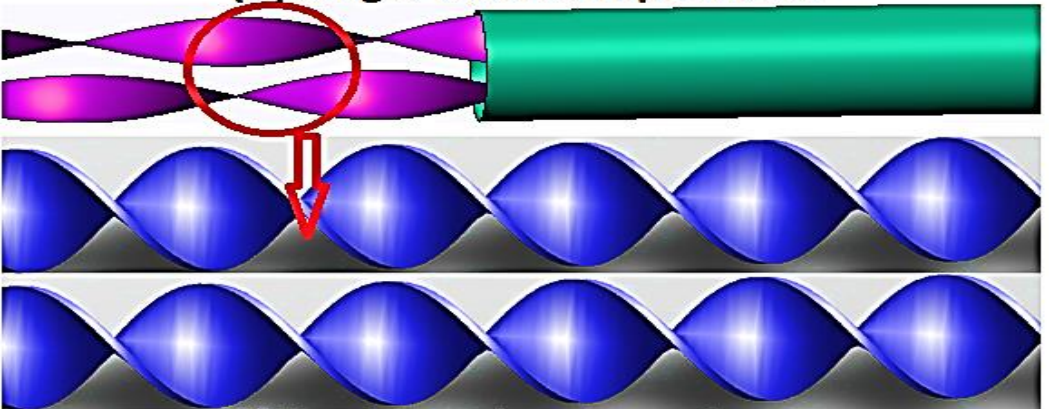

(B) Double twisted tape inserts

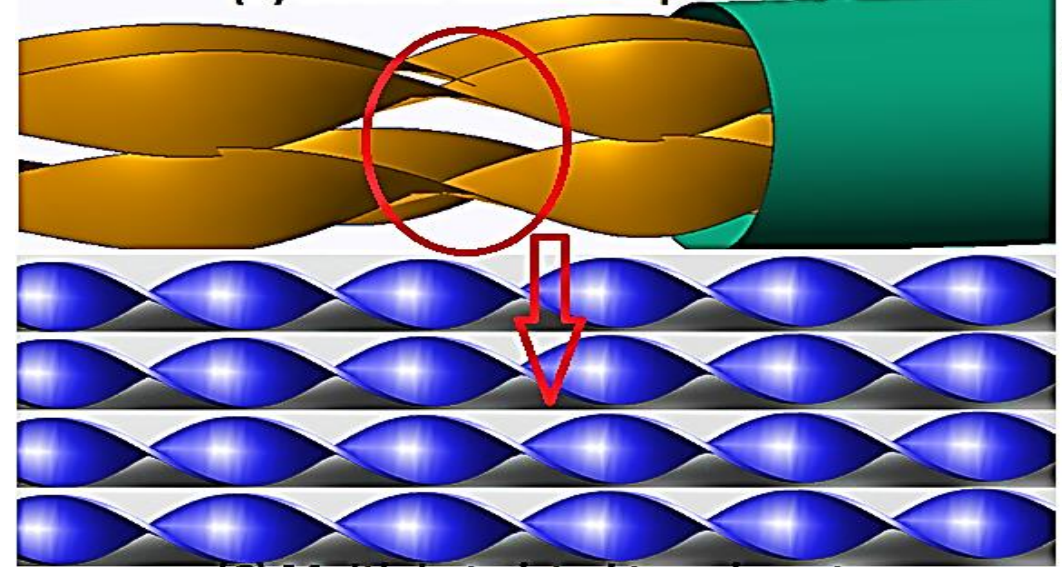

(c) Multiple twisted tape inserts
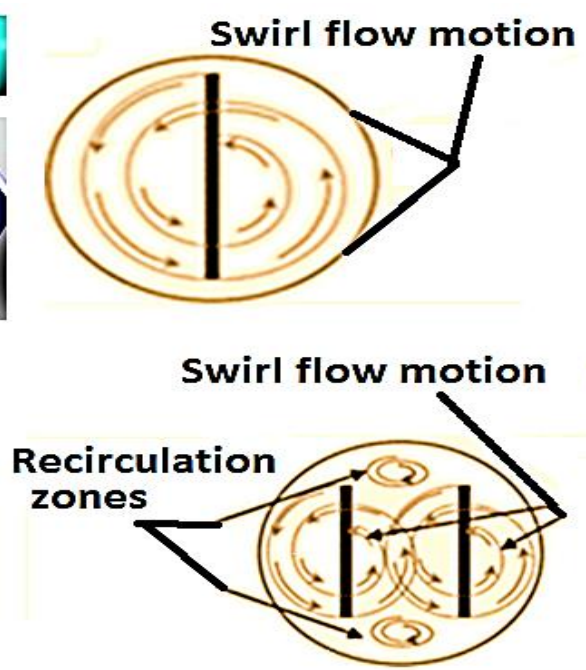

\section{Swirl flow motion}

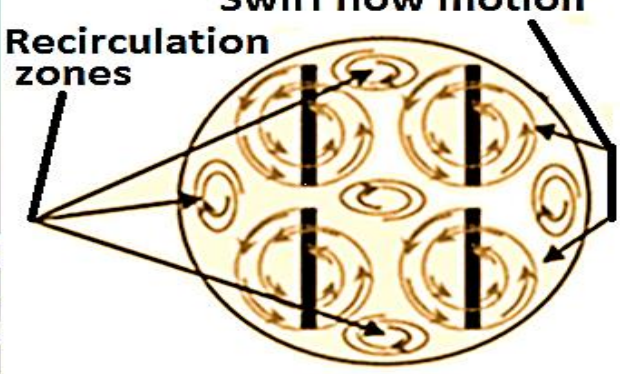

Fig. 4 Fluid flow pattern (A) single tape insert (B) double tape insert (C) multiple tape insert 


\section{CONCLUSIONS}

This article presents a critical review of work done in the area of hydrodynamic and thermal performance using twisted tapes. The effect of various twisted tape inserts parameters on hydrodynamic and thermal performance are discussed in detail. The following conclusions can be drawn:

1. The applications of twisted tape inserts in a heat exchanger tube are an efficient method to enhance the heat transfer to fluid flow in the round heat exchanger tube. The reduction of the twist pitch values and tube diameter ratio tends to increase the heat transfer rate and pressure drop as well.

2. The twist angle is the most significant structural factor. A higher twist angle leads to larger hydrodynamic and thermal performance. More the twist angle, the higher tangential velocity will be created. As the twist angle increases, the hydrodynamic and thermal performance decreases slowly.

3. Reducing values of the twist pitch to tube diameter ratio, lead to increased values of heat transfer rate and pressure drop as well. Swirl flow helps in decreasing the boundary layer thickness of the hot air flowing and rises thee residence time of hot air in the inner tube.

4. Augmentation of thermal performance in full length twisted tape is better than the twist fitted with rod and spacer. The decrease in heat transfer augmentation in twist fitted with rod is minimum compared to twist fitted with rod is minimum compared to twist fitted with spacer. The decrease in pressure drop is better for twist fitted with spacer compared to twist fitted with rod.

5. V-cut twisted tape offered a higher local Nusselt number, local friction factor and also thermal hydraulic performance as compared to plain twisted tape. In addition, the influence of the depth ratio was more dominant than that of the width ratio for all the flow parameters.

6. Using any kind of twisted tape leads to thermal hydraulic improvement which is more substantial for lower values of excess air flow rate. Comparison of heat transfer performance shows that the improvement of convection heat transfer coefficient is more than total heat transfer coefficient.

7. Among the entire twisted tape elements examined, the multiple twisted tape inserts have the maximum value of hydrodynamic and thermal performance than that of other twisted tape shapes for the examined range of twisted tape parameters.

\section{NOMENCLATURE}

$\begin{array}{cl}D_{r s} & \text { Diameter of Tube }[\mathrm{m}] \\ d_{r s} & \text { Director diameter }[\mathrm{m}] \\ P_{r s} & \text { Wetted perimeter }[\mathrm{m}] \\ e_{r s} & \text { Diameter of wire }[\mathrm{m}] \\ h_{r s} & \text { Heat transfer coef ficient }\left(\mathrm{W} / \mathrm{m}^{2} \mathrm{~K}\right) \\ S_{r s} & \text { Swirlparameter }(\mathrm{m}) \\ q_{r s} & \text { Heat flux }\left(\mathrm{W} / \mathrm{m}^{2}\right) \\ G_{r s} & \text { Graetz number } \\ f_{r s} & \text { Friction factor } \\ P_{r s} / H_{r s} & \text { Rib pitch ratio } \\ P r_{r s} & \text { Prandtl number } \\ \mathrm{g} & \text { Acceleration due to gravity } \\ C F D & \text { Computational fluid dynamics } \\ H E T & \text { Heat exchanger tube } \\ T T & \text { Twisted tape } \\ T T T & \text { Typical Twisted tape } \\ W V G & \text { Winglet type vortex generators } \\ P C R & \text { Perforated conical- ring }\end{array}$

$\begin{array}{cl}R e_{r s} & \text { Reynolds number } \\ N u_{r s} & \text { Nusselt number } \\ y_{r s} \& Y_{r s} & \text { Twist ratio of TT } \\ R_{r s} & \text { Rayleigh number } \\ & \text { REFERENCES }\end{array}$

Abolarin, S. M., Everts, M., \& Meyer, J. P. (2019). Heat transfer and pressure drop characteristics of alternating clockwise and counter clockwise twisted tape inserts in the transitional flow regime. International Journal of Heat and Mass Transfer, 133, 203-217. https://doi.org/https://doi.org/10.1016/j.ijheatmasstransfer.2018.12.10 7.

Agarwal, S. K., \& Raja Rao, M. (1996). Heat transfer augmentation for the flow of a viscous liquid in circular tubes using twisted tape inserts. International Journal of Heat and Mass Transfer, 39(17), 3547-3557.

https://doi.org/https://doi.org/10.1016/0017-9310(96)00039-7.

Akhavan-Behabadi, M. A., Kumar, R., Salimpour, M. R., \& Azimi, R. (2010). Pressure drop and heat transfer augmentation due to coiled wire inserts during laminar flow of oil inside a horizontal tube. International Journal of Thermal Sciences, 49(2), 373-379. https://doi.org/https://doi.org/10.1016/j.ijthermalsci.2009.06.004.

Al-Fahed, S., Chamra, L. M., \& Chakroun, W. (1998). Pressure drop and heat transfer comparison for both microfin tube and twisted-tape inserts in laminar flow. Experimental Thermal and Fluid Science, 18(4), 323-333.

https://doi.org/https://doi.org/10.1016/S0894-1777(98)10037-7.

Aroonrat, K., \& Wongwises, S. (2019). Experimental investigation of condensation heat transfer and pressure drop of R-134a flowing inside dimpled tubes with different dimpled depths. International Journal of Heat and Mass Transfer, 128, 783-793. https://doi.org/https://doi.org/10.1016/j.ijheatmasstransfer.2018.09.03 9.

Ayub, Z. H., Yang, D., Khan, T. S., Al-Hajri, E., \& Ayub, A. H. (2018). Performance characteristics of a novel shell and tube heat exchanger with shell side interstitial twisted tapes for viscous fluids application. Applied Thermal Engineering, 134, 248-255. https://doi.org/https://doi.org/10.1016/j.applthermaleng.2018.01.054.

Bartwal, A., Gautam, A., Kumar, M., Mangrulkar, C. K., \& Chamoli, S. (2018). Thermal performance intensification of a circular heat exchanger tube integrated with compound circular ring-metal wire net inserts. Chemical Engineering and Processing: Process Intensification, 124, 50-70. https://doi.org/https://doi.org/10.1016/j.cep.2017.12.002.

Bharadwaj, P., Khondge, A. D., \& Date, A. W. (2009). Heat transfer and pressure drop in a spirally grooved tube with twisted tape insert. International Journal of Heat and Mass Transfer, 52(7), 1938-1944.

htt https://doi.org/10.1016/j.ijheatmasstransfer.2008.08.038.

Bhuiya, M. M. K., Chowdhury, M. S. U., Saha, M., \& Islam, M. T. (2013). Heat transfer and friction factor characteristics in turbulent flow through a tube fitted with perforated twisted tape inserts. International Communications in Heat and Mass Transfer, 46, 49-57.

https://doi.org/https://doi.org/10.1016/j.icheatmasstransfer.2013.05.0 $\underline{12}$.

Bilen, K., Yapici, S., \& Celik, C. (2001). A Taguchi approach for investigation of heat transfer from a surface equipped with rectangular blocks. Energy Conversion and Management, 42(8), 951961.

https://doi.org/https://doi.org/10.1016/S0196-8904(00)00118-7. 
and pressure drop in tube fitted with serrated twisted tape. International Journal of Thermal Sciences, 46(5), 506-518. https://doi.org/https://doi.org/10.1016/j.ijthermalsci.2006.07.009.

Chang, S. W., Lees, A., \& Chang, H.-T. (2009). Influence of spiky twisted tape insert on thermal fluid performances of tubular airwater bubbly flow. International Journal of Thermal Sciences (Vol. 48).

https://doi.org/10.1016/j.ijthermalsci.2009.05.002.

Chang, S. W., Yang, T. L., \& Liou, J. S. (2007). Heat transfer and pressure drop in tube with broken twisted tape insert. Experimental Thermal and Fluid Science, 32(2), 489-501. https://doi.org/https://doi.org/10.1016/j.expthermflusci.2007.06.002.

Chompookham, T., Thianpong, C., Kwankaomeng, S., \& Promvonge, P. (2010). Heat transfer augmentation in a wedge-ribbed channel using winglet vortex generators. International Communications in Heat and Mass Transfer, 37(2), 163-169. https://doi.org/https://doi.org/10.1016/j.icheatmasstransfer.2009.09.0 $\underline{12}$.

Datt, R., Singh Bhist, M., Darshan Kothiyal, A., Maithani, R., \& Kumar, A. (2018). Effect of square wing with combined solid ring twisted tape inserts on heat transfer and fluid flow of a circular tube heat exchanger. International Journal of Green Energy (Vol. 15). https://doi.org/10.1080/15435075.2018.1525552.

Eiamsa-ard, S., Nivesrangsan, P., Chokphoemphun, S., \& Promvonge, P. (2010). Influence of combined non-uniform wire coil and twisted tape inserts on thermal performance characteristics. International Communications in Heat and Mass Transfer, 37(7), $850-856$.

https://doi.org/https://doi.org/10.1016/j.icheatmasstransfer.2010.05.0 $\underline{12}$.

Eiamsa-ard, S., \& Promvonge, P. (2011). Influence of Double-sided Delta-wing Tape Insert with Alternate-axes on Flow and Heat Transfer Characteristics in a Heat Exchanger Tube. Chinese Journal of Chemical Engineering, 19(3), 410-423. https://doi.org/https://doi.org/10.1016/S1004-9541(11)60001-3.

Eiamsa-ard, S., Thianpong, C., \& Eiamsa-ard, P. (2010). Turbulent heat transfer enhancement by counter/co-swirling flow in a tube fitted with twin twisted tapes. Experimental Thermal and Fluid Science, 34(1), 53-62.

https://doi.org/https://doi.org/10.1016/j.expthermflusci.2009.09.002.

Eiamsa-ard, S., Thianpong, C., Eiamsa-ard, P., \& Promvonge, P. (2009). Convective heat transfer in a circular tube with short-length twisted tape insert. International Communications in Heat and Mass Transfer, 36(4), 365-371. https://doi.org/https://doi.org/10.1016/j.icheatmasstransfer.2009.01.0 $\underline{06}$.

Eiamsa-ard, S., Thianpong, C., Eiamsa-ard, P., \& Promvonge, P. (2010). Thermal characteristics in a heat exchanger tube fitted with dual twisted tape elements in tandem. International Communications in Heat and Mass Transfer, 37(1), 39-46. https://doi.org/https://doi.org/10.1016/j.icheatmasstransfer.2009.08.0 $\underline{10}$.

Eiamsa-ard, S., Thianpong, C., \& Promvonge, P. (2006). Experimental investigation of heat transfer and flow friction in a circular tube fitted with regularly spaced twisted tape elements. International Communications in Heat and Mass Transfer, 33(10), 1225-1233.

https://doi.org/https://doi.org/10.1016/j.icheatmasstransfer.2006.08.0 $\underline{02}$.

Eiamsa-ard, S., \& Wongcharee, K. (2018). Convective heat transfer with non-uniform twisted tape. International Journal of Mechanical Sciences, $146-147$, 337-354. https://doi.org/https://doi.org/10.1016/j.ijmecsci.2018.07.040.

Eiamsa-ard, S., \& Wongcharee, K. (2013). Heat transfer characteristics in micro-fin tube equipped with double twisted tapes: Effect of twisted tape and micro-fin tube arrangements. Journal of Hydrodynamics, Ser. B, 25(2), 205-214. https://doi.org/https://doi.org/10.1016/S1001-6058(13)60355-8.

Eiamsa-ard, S., Wongcharee, K., Eiamsa-ard, P., \& Thianpong, C. (2010). Heat transfer enhancement in a tube using delta-winglet twisted tape inserts. Applied Thermal Engineering, 30(4), 310-318. https://doi.org/https://doi.org/10.1016/j.applthermaleng.2009.09.006.

Eiamsa-ard, S., Yongsiri, K., Nanan, K., \& Thianpong, C. (2012). Heat transfer augmentation by helically twisted tapes as swirl and turbulence promoters. Chemical Engineering and Processing: Process Intensification, 60, 42-48.

https://doi.org/https://doi.org/10.1016/j.cep.2012.06.001

Farnam, M., Khoshvaght-Aliabadi, M., \& Asadollahzadeh, M. J. (2018). Heat transfer intensification of agitated U-tube heat exchanger using twisted-tube and twisted-tape as passive techniques. Chemical Engineering and Processing - Process Intensification, 133, 137-147.

https://doi.org/https://doi.org/10.1016/j.cep.2018.10.002.

Han, H., Yu, R., Li, B., Zhang, Y., Wang, W., \& Chen, X. (2019). Multi-objective optimization of corrugated tube with loose-fit twisted tape using RSM and NSGA-II. International Journal of Heat and Mass Transfer, 131, 781-794. https://doi.org/https://doi.org/10.1016/j.ijheatmasstransfer.2018.10.12 $\underline{8}$.

Hong, Y., Du, J., Li, Q., Xu, T., \& Li, W. (2019). Thermal-hydraulic performances in multiple twisted tapes inserted sinusoidal rib tube heat exchangers for exhaust gas heat recovery applications. Energy Conversion and Management, 185, 271-290. https://doi.org/https://doi.org/10.1016/j.enconman.2019.01.074.

Ibrahim, E. Z. (2011). Augmentation of laminar flow and heat transfer in flat tubes by means of helical screw-tape inserts. Energy Conversion and Management, 52(1), 250-257. https://doi.org/https://doi.org/10.1016/j.enconman.2010.06.065.

Jaisankar, S., Radhakrishnan, T. K., \& Sheeba, K. N. (2008). Experimental Studies on Heat Transfer and Friction Factor Characteristics of Forced Circulation Solar Water Heater System Fitted with Left-Right Twisted Tapes, 9, 199-206. https://doi.org/10.1016/j.enconman.2010.11.024.

Jaisankar, S., Radhakrishnan, T. K., \& Sheeba, K. N. (2011). Experimental studies on heat transfer and thermal performance characteristics of thermosyphon solar water heating system with helical and Left - Right twisted tapes. Energy Conversion and Management, 52(5), 2048-2055.

https://doi.org/10.1016/j.enconman.2010.11.024.

Jaisankar, S., Radhakrishnan, T. K., Sheeba, K. N., \& Suresh, S. (2009). Experimental investigation of heat transfer and friction factor characteristics of thermosyphon solar water heater system fitted with spacer at the trailing edge of Left - Right twisted tapes. Energy Conversion and Management, 50(10), 2638-2649. https://doi.org/10.1016/j.enconman.2009.06.019.

Karami, A., Rezaei, E., Shahhosseni, M., \& Aghakhani, M. (2012). Optimization of heat transfer in an air cooler equipped with classic twisted tape inserts using imperialist competitive algorithm. Experimental Thermal and Fluid Science, 38, 195200.https://doi.org/https://doi.org/10.1016/j.expthermflusci.2011.12.0 
Kongkaitpaiboon, V., Nanan, K., \& Eiamsa-ard, S. (2010). Experimental investigation of heat transfer and turbulent flow friction in a tube fitted with perforated conical-rings. International Communications in Heat and Mass Transfer, 37(5), 560-567. https://doi.org/https://doi.org/10.1016/j.icheatmasstransfer.2009.12.0 $\underline{15}$.

Krishna, S. R., Pathipaka, G., \& Sivashanmugam, P. (2009). Heat transfer and pressure drop studies in a circular tube fitted with straight full twist. Experimental Thermal and Fluid Science, 33(3), 431-438.

https://doi.org/https://doi.org/10.1016/j.expthermflusci.2008.10.007.

Kumar, A., \& Kim, M. H. (2016). Heat transfer and fluid flow characteristics in air duct with various $\mathrm{V}$-pattern rib roughness on the heated plate: A comparative study. Energy, 103, 75-85. https://doi.org/10.1016/j.energy.2016.02.149.

Kumar, A., Maithani, R., \& Singh, A. (2017). Numerical and experimental investigation of enhancement of heat transfer in dimpled rib heat exchanger tube. Heat and Mass Transfer. https://doi.org/10.1007/s00231-017-2080-x.

Kumar, S., Kothiyal, A. D., Bisht, M. S., \& Kumar, A. (2017). Turbulent heat transfer and nanofluid flow in a protruded ribbed square passage. Results in Physics, 7, 3603-3618. https://doi.org/https://doi.org/10.1016/j.rinp.2017.09.023.

Kumar, R., Kumar, A., Chauhan, R., Maithani, R. (2018).

Comparative study of effect of various blockage arrangements on thermal-hydraulic performance in a roughened air passage. Renewable and Sustanable Energy Reviews, 81, 447-463. https://doi.org/https://doi.org/10.1016/j.rser.2017.08.023

Kurtbaş, İ., Gülçimen, F., Akbulut, A., \& Buran, D. (2009). Heat transfer augmentation by swirl generators inserted into a tube with constant heat flux. International Communications in Heat and Mass Transfer, 36(8), 865-871. https://doi.org/https://doi.org/10.1016/j.icheatmasstransfer.2009.04.0 11.

Sunil K., Mangal B., Alok K., Rajesh M., Anil Kumar (2019). Effect of nanofluid flow and protrusion transverse ribs on thermal and hydrodynamic performance in square channel: An experimental investigation. Journal of Enhanced Heat Transfer, 26, 75-100. https://doi.org/https://doi.org/10.1615/JEnhHeatTransf.2018026042

Lei, Y., Li, Y., Jing, S., Song, C., Lyu, Y., \& Wang, F. (2017). Design and performance analysis of the novel shell-and-tube heat exchangers with louver baffles. Applied Thermal Engineering, 125, 870-879.

https://doi.org/https://doi.org/10.1016/j.applthermaleng.2017.07.081.

Li, X., Meng, J., \& Guo, Z. (2009). Turbulent flow and heat transfer in discrete double inclined ribs tube. International Journal of Heat and Mass Transfer, 52(3), 962-970. https://doi.org/https://doi.org/10.1016/j.ijheatmasstransfer.2008.07.02 7.

Li, X., Zhu, D., Yin, Y., Tu, A., \& Liu, S. (2019). Parametric study on heat transfer and pressure drop of twisted oval tube bundle with in line layout. International Journal of Heat and Mass Transfer, 135, 860-872.

https://doi.org/https://doi.org/10.1016/j.ijheatmasstransfer.2019.02.03 $\underline{1 .}$

Maddah, H., Alizadeh, M., Ghasemi, N., \& Wan Alwi, S. R. (2014). Experimental study of Al2O3/water nanofluid turbulent heat transfer enhancement in the horizontal double pipes fitted with modified twisted tapes. International Journal of Heat and Mass Transfer, 78, 1042-1054.
Meng, J.-A., Liang, X.-G., \& Li, Z.-X. (2005). Field synergy optimization and enhanced heat transfer by multi-longitudinal vortexes flow in tube. International Journal of Heat and Mass Transfer, 48(16), 3331-3337. https://doi.org/https://doi.org/10.1016/j.ijheatmasstransfer.2005.02.03 $\underline{5}$.

Murugesan, P., Mayilsamy, K., \& Suresh, S. (2010a). Heat Transfer and Friction Factor Studies in a Circular Tube Fitted with Twisted Tape Consisting of Wire-nails. Chinese Journal of Chemical Engineering, 18(6), 1038-1042. https://doi.org/https://doi.org/10.1016/S1004-9541(09)60166-X.

Murugesan, P., Mayilsamy, K., \& Suresh, S. (2010b). Turbulent Heat Transfer and Pressure Drop in Tube Fitted with Square-cut Twisted Tape. Chinese Journal of Chemical Engineering, 18(4), 609617.https://doi.org/https://doi.org/10.1016/S1004- 9541(10)60264-9.

Murugesan, P., Mayilsamy, K., \& Suresh, S. (2012). Heat Transfer in a Tube Fitted with Vertical and Horizontal Wing-Cut Twisted Tapes. Experimental Heat Transfer, 25(1), 30-47. https://doi.org/10.1080/08916152.2011.559567.

Maithani, R., \& Kumar, A. (2019). Correlations development for Nusselt number and friction factor in a dimpled surface heat exchanger tube. Experimental Heat Transfer, 1-22. https://doi.org/10.1080/08916152.2019.1573863

Murugesan, P., Mayilsamy, K., Suresh, S., \& Srinivasan, P. S. S. (2011). Heat transfer and pressure drop characteristics in a circular tube fitted with and without V-cut twisted tape insert. International Communications in Heat and Mass Transfer, 38(3), 329-334. https://doi.org/https://doi.org/10.1016/j.icheatmasstransfer.2010.11.0 10 .

Nagarajan, P. K., Mukkamala, Y., \& Sivashanmugam, P. (2010). Studies on heat transfer and friction factor characteristics of turbulent flow through a micro-finned tube fitted with left-right inserts. Applied Thermal Engineering, 30(13), 1666-1672. https://doi.org/https://doi.org/10.1016/j.applthermaleng.2010.03.025.

Nanan, K., Thianpong, C., Promvonge, P., \& Eiamsa-ard, S. (2014). Investigation of heat transfer enhancement by perforated helical twisted-tapes. International Communications in Heat and Mass Transfer, 52(Supplement C), 106-112. https://doi.org/https://doi.org/10.1016/j.icheatmasstransfer.2014.01.0 $\underline{18}$.

Naphon, P., Nuchjapo, M., \& Kurujareon, J. (2006). Tube side heat transfer coefficient and friction factor characteristics of horizontal tubes with helical rib. Energy Conversion and Management, 47(18), 3031-3044. https://doi.org/https://doi.org/10.1016/j.enconman.2006.03.023.

Pal, P. K., \& Saha, S. K. (2014). Experimental investigation of laminar flow of viscous oil through a circular tube having integral spiral corrugation roughness and fitted with twisted tapes with oblique teeth. Experimental Thermal and Fluid Science, 57, 301-309. https://doi.org/https://doi.org/10.1016/j.expthermflusci.2014.05.007. Piriyarungrod, N., Kumar, M., Thianpong, C., Pimsarn, M., Chuwattabakul, V., \& Eiamsa-ard, S. (n.d.). Intensification of thermo-hydraulic performance in heat exchanger tube inserted with multiple twisted-tapes. Applied Thermal Engineering. https://doi.org/https://doi.org/10.1016/j.applthermaleng.2018.02.097.

Ponnada, S., Subrahmanyam, T., \& Naidu, S. V. (2019). A comparative study on the thermal performance of water in a circular tube with twisted tapes, perforated twisted tapes and perforated twisted tapes with alternate axis. International Journal of Thermal Sciences, 136 , $530-538$. https://doi.org/https://doi.org/10.1016/j.ijthermalsci.2018.11.008. 
twisted tape and wire coil turbulators. Energy Conversion and Management, 49(11), 2949-2955. https://doi.org/https://doi.org/10.1016/j.enconman.2008.06.022.

Promvonge, P., \& Eiamsa-ard, S. (2007a). Heat transfer behaviors in a tube with combined conical-ring and twisted-tape insert. International Communications in Heat and Mass Transfer, 34(7), 849-859.

https://doi.org/https://doi.org/10.1016/j.icheatmasstransfer.2007.03.0 19.

Promvonge, P., \& Eiamsa-ard, S. (2007b). Heat transfer in a circular tube fitted with free-spacing snail entry and conical-nozzle turbulators. International Communications in Heat and Mass Transfer, 34(7), 838-848.

https://doi.org/https://doi.org/10.1016/j.icheatmasstransfer.2007. $\underline{03.020 .}$

Ray, S., \& Date, A. W. (2001). Laminar flow and heat transfer through square duct with twisted tape insert. International Journal of

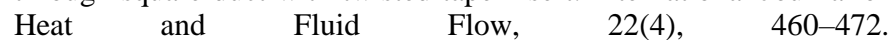
https://doi.org/https://doi.org/10.1016/S0142-727X(01)00078-9.

Saha, S. K. (2012). Thermohydraulics of laminar flow of viscous oil through a circular tube having axial corrugations and fitted with centre-cleared twisted-tape. Experimental Thermal and Fluid Science, 38 , 201-209. https://doi.org/https://doi.org/10.1016/j.expthermflusci.2011.12.008.

Saha, S. K., Bhattacharyya, S., \& Pal, P. K. (2012). Thermohydraulics of laminar flow of viscous oil through a circular tube having integral axial rib roughness and fitted with center-cleared twisted-tape. Experimental Thermal and Fluid Science, 41, 121-129. https://doi.org/https://doi.org/10.1016/j.expthermflusci.2012.04.004.

Salam, B., Biswas, S., Saha, S., \& Bhuiya, M. M. K. (2013). Heat Transfer Enhancement in a Tube using Rectangular-cut Twisted Tape Insert. Procedia Engineering, 56(Supplement C), 96-103. https://doi.org/https://doi.org/10.1016/j.proeng.2013.03.094.

Saraç, B. A., \& Bali, T. (2007). An experimental study on heat transfer and pressure drop characteristics of decaying swirl flow through a circular pipe with a vortex generator. Experimental Thermal and Fluid Science, 32(1), 158-165. https://doi.org/https://doi.org/10.1016/j.expthermflusci.2007.03.002.

Sarada, S. N., Raju, A. V. S. R., Radha, K. K., \& Sunder, L. S. (2010). Enhancement of heat transfer using varying width twisted tape inserts, 2(6), 107-118. https://doi.org/https://doi.org/10.1016/ijnstng.2010.06.

Saravanan, A., \& Jaisankar, S. (2019). Heat transfer augmentation techniques in forced flow V-trough solar collector equipped with Vcut and square cut twisted tape. International Journal of Thermal Sciences, $\quad 140, \quad 59-70$ https://doi.org/https://doi.org/10.1016/j.ijthermalsci.2019.02.030.

Sarma, P. K., Kishore, P. S., Rao, V. D., \& Subrahmanyam, T. (2005). A combined approach to predict friction coefficients and convective heat transfer characteristics in A tube with twisted tape inserts for a wide range of $\mathrm{Re}$ and Pr. International Journal of Thermal Sciences, 44(4), 393-398. https://doi.org/https://doi.org/10.1016/j.ijthermalsci.2004.12.001.

Sarma, P. K., Subramanyam, T., Kishore, P. S., Rao, V. D., \& Kakac, S. (2003). Laminar convective heat transfer with twisted tape inserts in a tube. International Journal of Thermal Sciences,

42(9), 821-828. $\quad$ https://doi.org/https://doi.org/10.1016/S12900729(03)00055-3.
Drop in a Circular Tube Fitted with Twisted Tape Insert Having Continuous Cut Edges. Journal of Energy Storage, 19, 10-14. https://doi.org/https://doi.org/10.1016/j.est.2018.07.001.

Seemawute, P., \& Eiamsa-ard, S. (2010). Thermohydraulics of turbulent flow through a round tube by a peripherally-cut twisted tape with an alternate axis. International Communications in Heat and Mass Transfer, 37(6), 652-659. https://doi.org/https://doi.org/10.1016/j.icheatmasstransfer.2010.03.0 $\underline{05}$.

Shabanian, S. R., Rahimi, M., Shahhosseini, M., \& Alsairafi, A. A. (2011). CFD and experimental studies on heat transfer enhancement in an air cooler equipped with different tube inserts. International Communications in Heat and Mass Transfer, 38(3), 383-390. https://doi.org/https://doi.org/10.1016/j.icheatmasstransfer.2010.12.0 $\underline{15}$.

Singh, A., Kumar, A., \& Maithani, R. (2018). Experimental investigation of heat transfer and fluid flow behaviour in multiple square perforated twisted tape with square wing inserts heat exchanger tube. Heat and Mass Transfer. https://doi.org/10.1007/s00231-018-2290-x.

Singh Suri, A. R., Kumar, A., \& Maithani, R. (2017). Effect of square wings in multiple square perforated twisted tapes on fluid flow and heat transfer of heat exchanger tube. Case Studies in Thermal Engineering, 10(Supplement C), 28-43. https://doi.org/https://doi.org/10.1016/j.csite.2017.03.002.

Singh, V., Chamoli, S., Kumar, M., \& Kumar, A. (2016). Heat transfer and fluid flow characteristics of heat exchanger tube with multiple twisted tapes and solid rings inserts. Chemical Engineering and Processing: Process Intensification, 102, 156-168. https://doi.org/10.1016/j.cep.2016.01.013.

Suri, A. R. S., Kumar, A., \& Maithani, R. (2018). Experimental determination of enhancement of heat transfer in a multiple square perforated twisted tape inserts heat exchanger tube. Experimental Heat Transfer, 31(2), 85-105.

https://doi.org/10.1080/08916152.2017.1397814

Singh, Y., Kumar, A., Maithani, R., \& Verma, N. (2018). TiO2/H2O nanofluid flow and heat transfer analysis in $\mathrm{V}$-pattern with combined protrusion obstacle square channel: experimental analysis and CFD validation. International Journal of Ambient Energy, 1-20.

https://doi.org/10.1080/01430750.2018.1563807

Sivashanmugam, P., \& Suresh, S. (2006). Experimental studies on heat transfer and friction factor characteristics of laminar flow through a circular tube fitted with helical screw-tape inserts. Applied Thermal Engineering, 26(16), 1990-1997. https://doi.org/https://doi.org/10.1016/j.applthermaleng.2006.01.008.

Sivashanmugam, P., \& Suresh, S. (2007). Experimental studies on heat transfer and friction factor characteristics of turbulent flow through a circular tube fitted with regularly spaced helical screw-tape inserts. Applied Thermal Engineering, 27(8), 1311-1319. https://doi.org/https://doi.org/10.1016/j.applthermaleng.2006.10.035.

Suri, A. R. S., Kumar, A., \& Maithani, R. (2018). Experimental determination of enhancement of heat transfer in a multiple square perforated twisted tape inserts heat exchanger tube. Experimental Heat Transfer, 31(2), 85-105. https://doi.org/10.1080/08916152.2017.1397814.

Tan, X., Zhu, D., Zhou, G., \& Zeng, L. (2012). Experimental and numerical study of convective heat transfer and fluid flow in twisted oval tubes. International Journal of Heat and Mass Transfer, 55(17), 4701-4710.

https://doi.org/https://doi.org/10.1016/j.ijheatmasstransfer.2012.04.03 
Thianpong, C., Eiamsa-ard, P., Wongcharee, K., \& Eiamsa-ard, S. (2009). Compound heat transfer enhancement of a dimpled tube with a twisted tape swirl generator. International Communications in Heat and Mass Transfer, 36(7), 698-704. https://doi.org/https://doi.org/10.1016/j.icheatmasstransfer.2009.03.0 $\underline{26}$.

Wang, Y., Liu, P., Shan, F., Liu, Z., \& Liu, W. (2019). Effect of longitudinal vortex generator on the heat transfer enhancement of a circular tube. Applied Thermal Engineering, 148, 1018- 1028. https://doi.org/https://doi.org/10.1016/j.applthermaleng.2018.11.080.

Wongcharee, K., \& Eiamsa-ard, S. (2011). Enhancement of heat transfer using $\mathrm{CuO} /$ water nanofluid and twisted tape with alternate axis. International Communications in Heat and Mass Transfer, 38(6),

$742-748$. https://doi.org/https://doi.org/10.1016/j.icheatmasstransfer.2011.03.0 $\underline{11}$.

Wongcharee, K., \& Eiamsa-ard, S. (2011). Friction and heat transfer characteristics of laminar swirl flow through the round tubes inserted with alternate clockwise and counter-clockwise twisted-tapes. International Communications in Heat and Mass Transfer, 38(3), 348-352.

https://doi.org/https://doi.org/10.1016/j.icheatmasstransfer.2010.12.0

$\underline{07}$.
Yang, C. S., Jeng, D. Z., Yang, Y.-J., Chen, H.-R., \& Gau, C. (2011). Experimental study of pre-swirl flow effect on the heat transfer process in the entry region of a convergent pipe. Experimental Thermal and Fluid Science, 35(1), 73-81. https://doi.org/https://doi.org/10.1016/j.expthermflusci.2010.08.008.

Yilma, M., Comakli, O., Yapici, S., \& Sara, O. N. (2003). Heat transfer and friction characteristics in decaying swirl flow generated by different radial guide vane swirl generators. Energy Conversion and Management, 44(2), 283-300. https://doi.org/https://doi.org/10.1016/S0196-8904(02)00053-5.

Zhang, X., Liu, Z., \& Liu, W. (2013). Numerical studies on heat transfer and friction factor characteristics of a tube fitted with helical screw-tape without core-rod inserts. International Journal of Heat and Mass Transfer, 60(Supplement C),490-498. https://doi.org/https://doi.org/10.1016/j.ijheatmasstransfer.2013.01.04 1 .

Zhang, X., Liu, Z., \& Sgdsg, F. (2012). Numerical studies on heat transfer and flow characteristics for laminar flow in a tube with multiple helical screw tapes. International Journal of Thermal Sciences (Vol. 58).

https://doi.org/10.1016/j.ijthermalsci.2012.02.025. 